\title{
Platform and fine chemicals from woody biomass: demonstration and assessment of a novel biorefinery
}

\author{
Roy Nitzsche ${ }^{1}$ (D) Arne Gröngröft ${ }^{1}$ (D) - Jakob Köchermann ${ }^{1}$ (D) $\cdot$ Kathleen Meisel ${ }^{1} \cdot$ Hendrik Etzold $^{1} \cdot$ Marlen Verges $^{2}$. \\ Moritz Leschinsky ${ }^{2}$. Julian Bachmann ${ }^{3} \cdot$ Bodo Saake $^{3}$ (D) $\cdot$ Sandra Torkler $^{2} \cdot$ Katja Patzsch $^{2}$ (D) $\cdot$ Björn Rößiger $^{2} \cdot$ \\ Daniela Pufky-Heinrich ${ }^{2}$ (D) - Gerd Unkelbach ${ }^{2}$
}

Received: 23 December 2019 / Revised: 7 May 2020 / Accepted: 14 May 2020 / Published online: 9 June 2020

(C) The Author(s) 2020

\begin{abstract}
The aim of this study was the experimental demonstration and assessment of a novel lignocellulose biorefinery (LCB) for the integration of beech wood-based products as platform and fine chemicals. The process sequence included organosolv pulping followed by pulp bleaching, hydrothermal conversion of hemicellulose to xylose and its purification, fermentation of xylose to malic acid, and base-catalyzed lignin depolymerization (BCD). The resulting products were dissolving pulp, phenolic $\mathrm{BCD}$ oligomers, and malic acid. The state of the art for these technologies is their experimental proof of concept and validation at a laboratory- and pilot-scale and has a technology readiness level (TRL) of 3-4. By integrating and optimizing the single-process steps into one LCB, the TRL could be increased to 5. Based on the findings of the experimental studies, a LCB converting 50,000 dry metric tonnes ( $\widehat{=} 38.7 \mathrm{MW}$ ) of beech wood annually was simulated with Aspen Plus. Mass and energy balances showed that 14,616 dry metric tonnes of dissolving pulp, 5174 dry metric tonnes of BCD-oligomers, and 4077 dry metric tonnes of malic acid annually could be produced. The total energy efficiency is $40.3 \%$. The calculation of specific production costs demonstrated the marketability of dissolving pulp ( $1350 € / \mathrm{t})$ and BCD-oligomers $(2180 € / \mathrm{t})$, whereas malic acid $(4750 € / \mathrm{t})$ is not yet competitive. Environmental assessment showed reduced greenhouse gas (GHG) emissions from the production of BCD-oligomers and malic acid and higher GHG emissions from the production of dissolving pulp compared with the reference products. In total, the examined LCB would contribute to the mitigation of global warming.
\end{abstract}

Keywords Lignocellulose biorefinery $\cdot$ Organosolv pulping $\cdot$ Pulp bleaching $\cdot$ Base-catalyzed lignin depolymerization $\cdot$ Xylose valorization $\cdot$ Malic acid fermentation

\section{Introduction}

One of the urgent measures to stop global warming is the replacement of fossil resources as a feedstock of the global economy. An important part of this challenge is to develop technologies for the efficient conversion of biomass to fuels and chemicals. Due to their ubiquitous availability, wood and

Arne Gröngröft

arne.groengroeft@dbfz.de

1 DBFZ Deutsches Biomasseforschungszentrum gemeinnützige GmbH, Torgauer Straße 116, 04347 Leipzig, Germany

2 Fraunhofer Center for Chemical-Biotechnological Processes (CBP), Am Haupttor - Bau 1251, 06237 Leuna, Germany

3 Universität Hamburg, Chemical Wood Technology, Haidkrugsweg 1, 22885 Barsbüttel, Germany other lignocellulosic residues have the potential to become a valuable resource. In Germany, beech wood was identified as a promising feedstock for prospective lignocellulose biorefineries (LCB). Accounting for $15 \%$ of total forestland and $17 \%$ of total wood reserves, beech is the third most common tree species and has an unused potential of $1.3 \mathrm{Mt}$ of dry matter per year [1]. Although traditional pulping processes focus mainly on the valorization of cellulose, it is important for the overall efficiency of LCBs that hemicellulose and lignin are also recovered. Lignin and hemicellulose usually end up as fuel to provide heat and electricity to the process and for external use. New conversion processes lead to plant concepts with diversified product portfolios and new products for the bioeconomy. New pulp mills already show a strong tendency to include the production of specialty products from unused wood components. Thus, they produce not only pulp for the paper and board industry but also products for the chemical 
industry. Novel biorefinery concepts for the processing of all of the major wood components into value-added products should therefore be developed.

Among the different pulping processes, especially the organosolv process is considered appropriate for the valorization of all of the components of the wood [2]. It leads to the fractionation of beech wood to solid cellulose fibers, hemicellulose hydrolysate (HH), and pure, solid lignin. Furthermore, it benefits from relatively mild process conditions and easy-torecover solvents. In previous studies, organosolv pulping was developed at the Fraunhofer-Center for ChemicalBiotechnological Processes (CBP) (Leuna, Germany). A process using an ethanol-water mixture as solvent was successfully transferred from laboratory- to pilot-scale [3]. It was found though that product yields and mass balances of the organosolv process should be improved. Moreover, it was found necessary to develop processes that result in marketable products from all of the obtained wood fractions to achieve economic feasibility [4]. Thereby, a special focus was laid on the need for a valorization not only of the cellulose but also of the $\mathrm{HH}$ and the lignin [3].

The focus of previous studies was mainly on producing fermentable sugars from the cellulose. However, dissolving pulp has more than twice the market price of sugar and has become a very interesting product for the pulping industry [5]. Hence, dissolving pulp, produced by bleaching of the cellulose fibers, was selected as a primary product of the LCB in this study. In the valorization of cellulose fibers into dissolving pulp, the required degree of brightness, kappa number, and other important criteria for pulp characterization indicates that after the organosolv pulping a bleaching process is necessary. Peters and Höglinger [6] showed a possible bleaching sequence for raw cellulose fibers from ethanol-water pulping and concluded that dissolving pulp with characteristics similar to sulfite pulp can be obtained. However, the proposed bleaching sequence includes chemicals, such as calcium hypochlorite, which can no longer be used due to improved environmental standards. For this reason, it was necessary to develop a new suitable bleaching sequence to obtain dissolving pulp from the organosolv cellulose fibers.

The HH from the organosolv pulping contains a mixture of many soluble compounds from beech wood that are formed during the process. Of these, xylose oligomers and monomers are the most important, and, therefore, it seems reasonable to develop valorization processes. Several biochemical conversion processes and yeasts have been engineered in recent years to convert xylose to a number of products, such as ethanol, lactic acid, and fatty alcohols [7-9]. A prerequisite for the $\mathrm{HH}$ to be used for such processes is a sufficiently high concentration of fermentable xylose. For high yields, the remaining oligomers should also be hydrolyzed to monomers as much as possible and the xylose concentration should be increased. Furthermore, inhibitory effects of other substances in the hydrolysate should be studied and minimized. Hydrothermal treatment, which means a process in water at elevated temperature and pressure, seems to be a conversion process with good prospects to decompose the remaining hemicellulose to xylose [10-12]. Efficient, robust, and economical separation processes are then required, which remove potential inhibitors (e.g., carboxylic acids, furans, and phenolic compounds) and concentrate xylose. The membrane technology nanofiltration (NF) has the capability to remove water and other non-sugars without additional chemicals and phase changes [13-15]. Therefore, it consumes less materials and energy. Various microorganisms have been identified which can produce dicarboxylic acids, such as malic acid and xylonic acid [16-18]. Most of the studies on dicarboxylic acids were conducted on glucose, but it has also been shown that Aspergillus oryzae (DSM1863) can produce malic acid from xylose and glycerin [19]. Malic acid is currently used in the food and beverage industry, but it can also be used as a building block in the chemical industry for 1,4-butanediol production [20]. No studies, however, have as yet demonstrated either the pilot-scale biochemical production of malic acid or a process using microorganisms fed with wood hydrolysates instead of pure feedstock.

The lignin from organosolv pulping has a significantly higher quality and purity compared to other types of lignin (e.g., kraft lignin) [21]. Through depolymerization, the molecular weight of lignin can be greatly reduced and bio-based aromatic building blocks with an increased functionality can be produced. The base-catalyzed depolymerization (BCD) of lignin was found to be a promising approach, especially in combination with water or ethanol as a solvent for the lignin $[22,23]$. The BCD process yields a solid, powder-like phase containing larger oligomers from lignin and an oily liquid phase with monomers (e.g., phenol, guaiacol, syringol, and catechol) and dimers. This opens up new fields of application for the phenolic oligomers in already established and potential products (e.g., polyurethane and epoxy resins). Studies to analyze products of $\mathrm{BCD}$, identify reaction mechanisms, and optimize product yields have been conducted in laboratory- and pilotscale [24-26] and were recently repeated [27] using different kinds of lignin. Different downstream processes were studied to separate the organic phases from the water, including extraction with organic solvents and NF [28-31]. The BCD of lignin and the subsequent downstream processing should be transferred to pilot-scale to obtain product samples so that it can be included and evaluated within the overall LCB concept.

Hence, the state of the art for these technologies was considered the experimental proof of concept and their validation in laboratory- to pilot-scale, translating to a technology readiness level (TRL) of 3-4 [32]. However, the single processes had not yet been carried out with real feedstocks and their integration and optimization into one LCB could increase the TRL to 5. The overall aim of this study was thus the practical demonstration and assessment of an organosolv-based LCB producing 
dissolving pulp from cellulose, malic acid from hemicellulose, and BCD-oligomers from lignin. To do so, the whole process chain starting from organosolv pulping and followed by pulp bleaching, xylose valorization from $\mathrm{HH}$, fermentation of xylose to malic acid, and base-catalyzed lignin depolymerization (Fig. 1) was to be realized on pilot scale. Apart from the demonstration of the entire production chain, open issues in the individual process steps were addressed: In the organosolv pulping, increasing the resource and energy efficiency as well as the concentration of C5 sugars in the HH was found necessary. In particular, the reduction of waste water and other waste streams by recycling and developing a more efficient process for the precipitation of lignin were addressed. An environmentally acceptable bleaching sequence for the raw fibers had to be developed with the target that the quality requirements of dissolving pulp are met. To make use of the $\mathrm{HH}$, a process to obtain a fermentable solution with a high xylose concentration and low inhibitory effects had to be developed. The production of malic acid from xylose was to be scaled up from laboratory-scale experiments and tested on real $\mathrm{HH}$. In addition, a separation cascade for malic acid recovery had to be established. Objectives for the BCD of lignin were the optimization of the process toward specific phenolic derivatives and the development and optimization of the separation of the various phenolic fractions. Moreover, upscaling to pilot scale was aspired. Finally, the specific production costs of the products and the attributable greenhouse gas emissions were to be calculated based on mass and energy balances of the entire LCB.

\section{Materials and methods}

\subsection{Organosolv pulping}

Organosolv pulping was conducted in the LCB pilot plant of the Fraunhofer CBP in a $400 \mathrm{~L}$ batch reactor [33]. As feedstock for the pulping trials, screened beech wood chips for the production of dissolving pulp (provided by Lenzing AG, Austria) with a dry matter content of $50 \%$ were used. Pulping conditions were a pressure of $2.0 \mathrm{MPa}$, a temperature of $170{ }^{\circ} \mathrm{C}$, and a residence time of $130 \mathrm{~min}$. An 1:1 ethanolwater mixture $(\mathrm{w} / \mathrm{w})$ was used as solvent in a liquor-to-wood ratio of 3.2:1 (w/w). As catalyst, $1 \%$ sulfuric acid $\left(\mathrm{H}_{2} \mathrm{SO}_{4}\right)$ was added in a ratio of $0.8 \%(\mathrm{w} / \mathrm{w})$ to the dry wood matter. After pulping, two washing steps were carried out to extract remaining lignin from the cellulose fibers. In the first displacement washing, an 1:1 ethanol-water mixture $(\mathrm{w} / \mathrm{w})$ was used with a solvent-to-wood ratio of 10:1 (w/w). The washing was carried out for $60 \mathrm{~min}$ at a temperature of $100{ }^{\circ} \mathrm{C}$ and a pressure of 2.0 MPa. For the second displacement washing, pure water was used in a water-to-wood ratio of 13.6:1 (w/w) at $0.3 \mathrm{MPa}$ and $35^{\circ} \mathrm{C}$.

Subsequent to the pulping process and the washing steps, the remaining fiber suspension was disintegrated and dewatered in a screw press to reach a dry matter content of $30 \%$. From the liquid extracts of the pulping and the first washing step, lignin was precipitated by a patented distillation

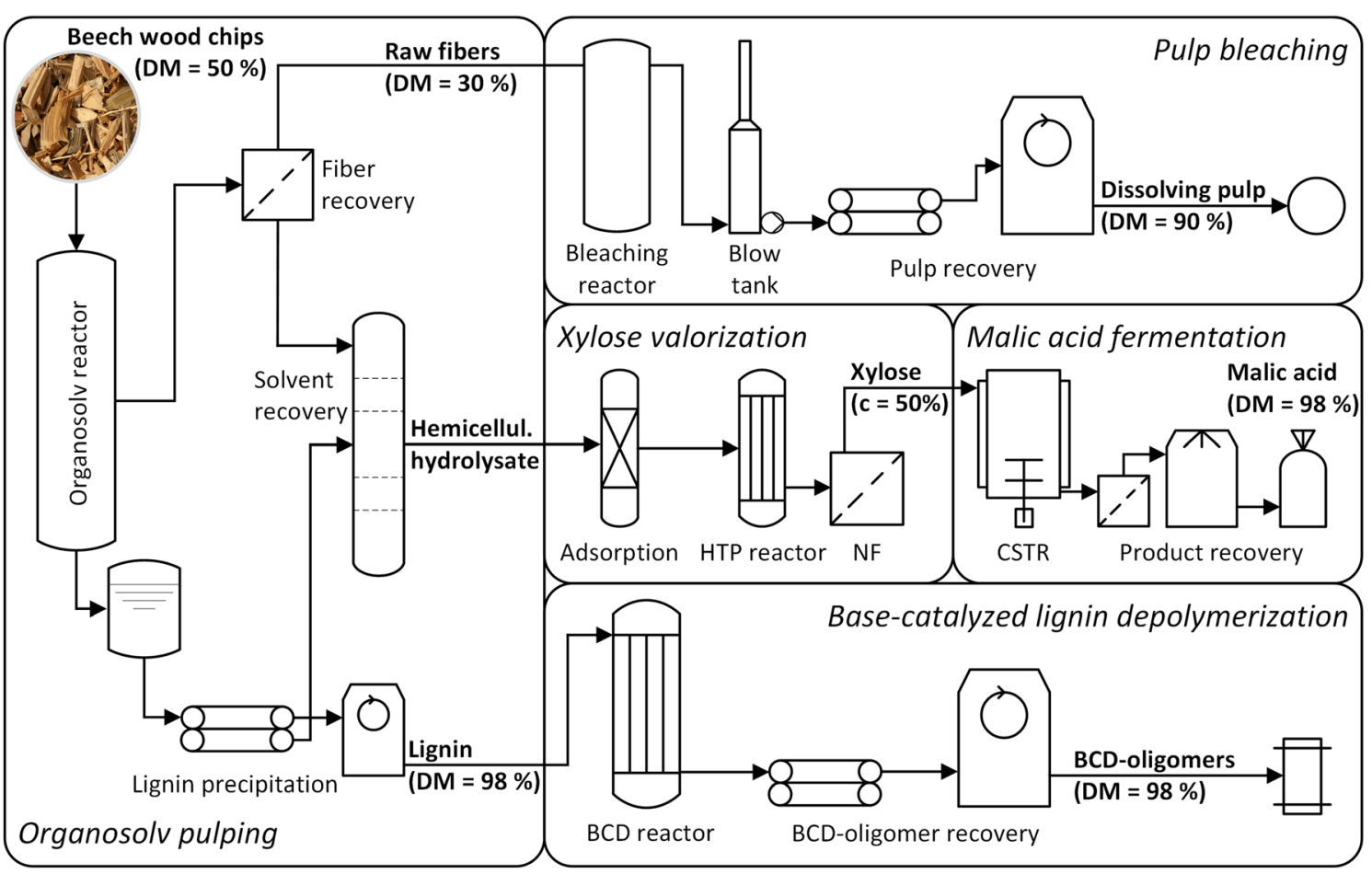

Fig. 1. Simplified scheme of the lignocellulose biorefinery for the production of dissolving pulp, malic acid, and BCD-oligomers from beech wood (DM, dry matter; c, concentration) 
process [34]. This process was carried out in pilot scale at the Fraunhofer CBP, according to process parameters established in laboratory-scale trials by Schulze et al. [35]. The ethanol was distilled off at $0.01 \mathrm{MPa}$ leading to a precipitation of the dissolved lignin from the mother liquor. Afterward, the solid lignin particles were filtered and dried to a dry matter content of $98 \%$ for subsequent depolymerization. Ethanol was recovered from the supernatant by rectification, yielding the $\mathrm{HH}$ as residual liquid product. It contains oligomeric sugars, monomeric sugars, furans, and carboxylic acids hydrolyzed from the hemicellulose during pulping as well as residual lignin and its phenolic derivatives. Within this study, the $\mathrm{HH}$ was purified and fermented to malic acid.

\subsection{Pulp bleaching}

In the bleaching experiments, cellulose fibers from the organosolv pulping were treated to produce dissolving pulp for use in the viscose process. For this purpose, the following specifications must be fulfilled: degree of brightness $>90 \%$ ISO, kappa number $<0.4$, intrinsic viscosity (a measure of the degree of polymerization) between 400 and $600 \mathrm{~mL} / \mathrm{g}$, and content of hemicellulose $<4 \%(\mathrm{w} / \mathrm{w})$. To fulfill these requirements, a bleaching sequence was developed which consisted of (a) pulp screening and washing, (b) cold caustic extraction, (c) oxygen delignification, (d) chlorine dioxide bleaching, and (e) hydrogen peroxide bleaching. In the following sections, the conditions and materials for each process step are briefly explained.

(a) During the screening process, the fibers were first defibrillated for $5 \mathrm{~min}$ in a pulper at a medium stock consistency of $30 \%$ to $40 \%$. The fiber suspension was then transferred to a vibrating screener with $0.15 \mathrm{~mm}$ slotted screens and repeatedly flushed with deionized water. The screened pulp was dewatered in a centrifuge for $10 \mathrm{~min}$, and the dry matter was determined. Additionally, the dry matter of the shivers was determined to identify the total shiver content.

(b) The cold caustic extraction was conducted to reduce the hemicellulose content of the pulp before delignification and bleaching. As extraction medium, an $\mathrm{NaOH}$ solution with a concentration of $100 \mathrm{~g} / \mathrm{L}$ was prepared. The process was performed at $35^{\circ} \mathrm{C}$ for $30 \mathrm{~min}$. The initial $\mathrm{pH}$ value was 13.0 , the stock consistency was $15 \%$, and the $\mathrm{NaOH}$ concentration in the liquid phase was $8 \%$.

(c) Oxygen delignification was conducted using a stainless steel autoclave with Teflon insert, which rotated overhead in an electrically heated silicone oil bath. The autoclave was charged with the bleaching suspension and pressurized with $\mathrm{O}_{2}$ to a pressure of $0.8 \mathrm{MPa}$. The oxygen delignification was carried out at $80^{\circ} \mathrm{C}$ for $90 \mathrm{~min}$ (including a 30 min heat-up period). The initial $\mathrm{pH}$ was 12.7 , and the stock consistency was $10 \%$. As alkali source in the oxygen delignification, $5 \%$ $\mathrm{NaOH}$ based on the dry matter of pulp was used. To stabilize the cellulose, $\mathrm{MgSO}_{4}$ was added in a concentration of $0.2 \%$ based on the dry matter of pulp.

(d) In the chlorine dioxide bleaching stage, the volatile $\mathrm{ClO}_{2}$ was mixed rapidly with the pulp in a concentration of $2 \%$ based on the dry matter of pulp. Then, the bleaching was performed at $60^{\circ} \mathrm{C}$ for 180 min with an initial $\mathrm{pH}$ of 6.7 and a stock consistency of $10 \%$. The $\mathrm{pH}$ of the pulp suspension was adjusted by the addition of $\mathrm{NaOH}$ in a concentration of $0.6 \%$ based on the dry matter of pulp. In addition, the complexing agent ethylenediaminetetraacetic acid (EDTA; purity $\geq 97 \%$ ) was added in a concentration of $0.1 \%$ based on the dry matter of pulp to avoid the transition metal-catalyzed decomposition of $\mathrm{H}_{2} \mathrm{O}_{2}$, which is applied in the following bleaching stage [36]. The $\mathrm{ClO}_{2}$ consumption after the process was determined via an iodometric titration and is given as percentage of the amount of $\mathrm{ClO}_{2}$ used.

(e) In the hydrogen peroxide bleaching, an $\mathrm{NaOH}$ solution was used as the bleaching agent in a concentration of $0.8 \%$ based on the dry matter of pulp. Process conditions were a temperature of $60^{\circ} \mathrm{C}$, a bleaching duration of $120 \mathrm{~min}$, an initial $\mathrm{pH}$ of 11.4 , and stock consistency of $10 \%$. The concentration of $\mathrm{H}_{2} \mathrm{O}_{2}$ in solution as well as the residual $\mathrm{H}_{2} \mathrm{O}_{2}$ content of the bleaching liquor was determined by iodometric titration to calculate the $\mathrm{H}_{2} \mathrm{O}_{2}$ consumption.

\subsection{Xylose valorization from hemicellulose}

To obtain fermentable xylose from the $\mathrm{HH}$, a purification sequence consisting of removal of lignin fractions by adsorption, hydrolysis of oligomeric xylose to monomeric xylose, and the purification of the monomeric xylose by means of NF was applied. The HH from organosolv pulping was provided by the Fraunhofer CBP with the composition listed in Table 1. Before adsorption and NF experiments, the $\mathrm{pH}$ of the feed solutions was adjusted from 1.6 to 2.7 with the addition of a $5 \mathrm{M} \mathrm{NaOH}$, prefiltered by a $150 \mathrm{kDa}$ ultrafiltration

Table 1. Composition of hemicellulose hydrolysate $(\mathrm{HH})$, product solution from hydrothermally treated hemicellulose hydrolysate (HTHH), and nanofiltration retentate (NFR) from HTHH at a volume reduction $\left(V R=V_{\text {perm }} / V_{f}\right)$ of 0.6

\begin{tabular}{lccc}
\hline Components & HH & HTHH & NFR from HTHH \\
\hline & $(\mathrm{g} / \mathrm{L})$ & $(\mathrm{g} / \mathrm{L})$ & $(\mathrm{g} / \mathrm{L})$ \\
Oligo-xylose & 22.8 & 2.70 & 6.75 \\
Xylose & 34.2 & 51.4 & 126 \\
Glucose & 2.80 & 4.50 & 11.2 \\
5-HMF & 0.80 & 1.20 & 1.73 \\
Furfural & n.d. & 0.80 & 1.04 \\
Acetic acid & 3.90 & 3.70 & 3.91 \\
\hline
\end{tabular}


ceramic membrane to remove suspended solids from the liquid fraction and stored at $4{ }^{\circ} \mathrm{C}$ prior to further processing.

Through adsorption on resins, lignin and its phenolic degradation products were removed from the $\mathrm{HH}$. For the adsorption experiments, SEPABEADS SP700 (Mitsubishi Chemical Corporation) and $\mathrm{HH}$ were mixed in a $500 \mathrm{~mL}$ beaker in an adsorbent-to-solution ratio of 1:5 (w/v) for $90 \mathrm{~min}$ (temperature of $25{ }^{\circ} \mathrm{C}$, stirring rate of $500 \mathrm{rpm}$ ). A Nutsche-type filter was used for the separation of the loaded adsorbents from the liquid phase. The moment at which the adsorbents were added to the $\mathrm{HH}$ was considered as time zero for the experiments. To identify the equilibrium time and concentration, small-volume liquid samples of $3 \mathrm{~mL}$ were collected during the trials at predetermined time intervals. Detailed information concerning the adsorption process, modeling of isotherms, analytics, and desorption studies has already been published [37].

The oligomeric xylose in the $\mathrm{HH}$ was hydrolyzed by hydrothermal treatment in a continuous tube reactor with a total length of $6.8 \mathrm{~m}$ and an internal diameter of $7 \mathrm{~mm}$. The $\mathrm{HH}$ was pressurized to $5.0 \mathrm{MPa}$ by a membrane pump and fed through a preheater to the tube reactor. Both the preheater and the tube reactor were heated electrically. The hydrothermal treatment was conducted at temperatures of 160,180 , and $200{ }^{\circ} \mathrm{C}$ with retention times between 2.5 and 23 min to determine the best reaction conditions. After passing through the reactor, the hydrothermally treated $\mathrm{HH}$ was cooled to ambient temperature by a water-cooled heat exchanger before it was released to intermediate storage by a pressure control valve. Detailed information to the hydrothermal conversion of the $\mathrm{HH}$ and analytics of the reaction products are described in a previous study [12].

Potential inhibitors to subsequent fermentations were separated by NF from the monomeric xylose after the hydrothermal treatment. The aim was to have water and small inhibitory molecules, such as furfural, 5-hydroxymethylfurfural (5HMF), and acidic acid, to permeate through the membrane. This would purify and concentrate the monomeric xylose in the retentate. The NF was conducted with an Alfa Laval LabStak M20 plate-and-frame membrane module. The commercially available flat sheet membrane Alfa Laval NF was used, which is made of thin-film composite polyamide supported by polyester and has a molecular weight cut-off of 300 Da. The filtration area $\left(A_{m}\right)$ was $0.036 \mathrm{~m}^{2}$. For the determination of appropriate process parameters, the transmembrane pressure was varied between 1.0 and $4.0 \mathrm{MPa}$, the temperature was varied between 25 and $55^{\circ} \mathrm{C}$, and the cross-flow velocity was varied between 0.5 and $1.5 \mathrm{~m} / \mathrm{s}$ at a constant $\mathrm{pH}$ of 2.7 . Parameter screening experiments were conducted with recirculation of both permeate and retentate to the feed. At appropriate process conditions, the monomeric xylose was concentrated in the NF retentate to at least $120 \mathrm{~g} / \mathrm{L}$. The permeate flux $J$ was calculated from the permeate volume $\left(V_{\text {perm }}\right)$ collected during a time $(t)$ of $1 \mathrm{~min}$ in a volumetric cylinder $\left(J=V_{\text {perm }} /\right.$ $\left.\left(A_{m} t\right)\right)$. Small amounts of samples $(10 \mathrm{~mL})$ were taken from the permeate (perm) and feed $(f)$ for the determination of the component concentrations $\left(c_{i}\right)$ and the calculation of observed retentions $R_{\text {obs }}\left(R_{i, \text { obs }}=\left(1-c_{i, \text { perm }} / c_{i, f}\right) \cdot 100 \%\right)$. Methods used for the analysis of oligomeric xylose, glucose, monomeric xylose, 5-HMF, furfural, and acetic acid are described in Köchermann et al. [12, 38].

\subsection{Malic acid fermentation}

Aspergillus oryzae ATCC 56747 was obtained from the DSMZ (Deutsche Sammlung von Mikroorganismen und Zellkulturen, Braunschweig, Germany) culture collection and was routinely grown on potato glucose agar with $1 \mathrm{M}$ $\mathrm{KCl}$ at a temperature of $30^{\circ} \mathrm{C}$ for $120 \mathrm{~h}$. Conidia were harvested with $25 \%$ glycerol from plates, filtered through a Miracloth filter and were counted and diluted to $10^{7}$ conidia/ $\mathrm{mL}$. L-Malic acid production was performed in a two-step system consisting of a preculture and a main culture. The preculture medium contained $36.4 \mathrm{~g} / \mathrm{L}$ xylose, $4 \mathrm{~g} / \mathrm{L}$ $\left(\mathrm{NH}_{4}\right)_{2} \mathrm{SO}_{4}, 0.75 \mathrm{~g} / \mathrm{L} \mathrm{KH}_{2} \mathrm{PO}_{4}, 0.748 \mathrm{~g} / \mathrm{L} \mathrm{K}_{2} \mathrm{HPO}_{4}, 0.1 \mathrm{~g} / \mathrm{L}$ $\mathrm{MgSO}_{4} \cdot 7 \mathrm{H}_{2} \mathrm{O}, 0.1 \mathrm{~g} / \mathrm{L} \mathrm{CaCl}_{2} \cdot 2 \mathrm{H}_{2} \mathrm{O}, 0.005 \mathrm{~g} / \mathrm{L} \mathrm{NaCl}$, and $0.005 \mathrm{~g} / \mathrm{L} \mathrm{FeSO}_{4} \cdot 7 \mathrm{H}_{2} \mathrm{O}$ and was sterilized by autoclaving and filtration. The main culture medium contained $111.5 \mathrm{~g} / \mathrm{L}$ xylose, $1.4 \mathrm{~g} / \mathrm{L}\left(\mathrm{NH}_{4}\right)_{2} \mathrm{SO}_{4}, 0.13 \mathrm{~g} / \mathrm{L} \mathrm{KH}_{2} \mathrm{PO}_{4}, 0.1 \mathrm{~g} / \mathrm{L}$ $\mathrm{K}_{2} \mathrm{HPO}_{4}, 0.1 \mathrm{~g} / \mathrm{L} \mathrm{MgSO}_{4} \cdot 7 \mathrm{H}_{2} \mathrm{O}, 0.1 \mathrm{~g} / \mathrm{L} \mathrm{CaCl}{ }_{2} \cdot 2 \mathrm{H}_{2} \mathrm{O}, 0.005$ $\mathrm{g} / \mathrm{L} \mathrm{NaCl}$, and $0.06 \mathrm{~g} / \mathrm{L} \mathrm{FeSO}_{4} \cdot 7 \mathrm{H}_{2} \mathrm{O}$. For $\mathrm{pH}$ regulation, $90 \mathrm{~g} /$ $\mathrm{L} \mathrm{CaCO}_{3}$ was added.

For fermentation in a $1000 \mathrm{~L}$ batch reactor, a two-stage seed train was chosen. The first stage was carried out in a 10 L bioreactor (Proreact 4P, Frings; $6.5 \mathrm{~L}$ preculture medium), which was inoculated with $2 \cdot 10^{5}$ conidia/mL. After $30 \mathrm{~h}$ of cultivation, the fungal biomass was transferred to a $100 \mathrm{~L}$ bioreactor (Proreact 15P, Frings; $65 \mathrm{~L}$ pre-culture medium) as the second seed and after a further $40 \mathrm{~h}$ to the main culture medium in the $1000 \mathrm{~L}$ bioreactor (Proreact 35P, Frings). For the malic acid production, $650 \mathrm{~L}$ of the main culture medium was used. The process was operated at a pressure of $0.15 \mathrm{MPa}$, a temperature of $35^{\circ} \mathrm{C}$, an aeration rate of $0.25 \mathrm{vvm}$, and an initial stirrer speed of $239 \mathrm{rpm}$. Dissolved $\mathrm{O}_{2}$ was controlled at $20 \%$ by the addition of $\mathrm{N}_{2}$. An energy dissipation/circulation factor $(\mathrm{EDCF})$ of $20 \mathrm{~W} /\left(\mathrm{m}^{3} \mathrm{~s}\right)$ was used. Samples were taken approximately every $24 \mathrm{~h}$ and analyzed for dry matter content, sugar, and malic acid concentration.

The determination of the dry matter content was carried out gravimetrically and was used to analyze the growth of Aspergillus oryzae. A sample of $1 \mathrm{~mL}$ was treated with 4 $\mathrm{mL}$ of $2 \mathrm{M} \mathrm{HCl}$ to dissolve the $\mathrm{CaCO}_{3}$. The biomass was then separated from the liquid phase by vacuum filtration through a glass fiber filter and dried at $105{ }^{\circ} \mathrm{C}$ for $24 \mathrm{~h}$ in a drying oven. The analysis of sugars (xylose and glucose) and carboxylic acids (malic, succinic, fumaric, and citric acids) as well as other sample components, such as 5-HMF, was performed by HPLC with an Aminex HPX-87H column. The eluent 
was $5 \mathrm{mM} \mathrm{H}_{2} \mathrm{SO}_{4}$. Measurement and quantification were performed with a coupled refractive index detector (RID) and diode array detector (DAD). The malic acid was quantified by the DAD signal at $215 \mathrm{~nm}$. All other components were evaluated using the RID signal. The analysis was based on the retention times of standard substances.

Downstream processing was carried out by the following: (a) acidification of the fermentation broth to $\mathrm{pH} 3.3$ with a $70 \% \mathrm{H}_{3} \mathrm{PO}_{4}$ solution for $60 \mathrm{~min}$ at ambient temperature, (b) inactivation of the microorganisms at $121^{\circ} \mathrm{C}$ for $20 \mathrm{~min}$, (c) removal of biomass and $\mathrm{Ca}_{3}\left(\mathrm{PO}_{4}\right)_{2}$ by filtration using a filter press (DELLA TOFFOLA, Tiemann) at $70{ }^{\circ} \mathrm{C}$, (d) crystallization by cooling from 40 to $0^{\circ} \mathrm{C}$ with a cooling rate of $5^{\circ} \mathrm{C} / \mathrm{h}$ in a stirred stainless steel vessel, (e) filtration of the crystals via a metal sieve with a pore size of $1 \mu \mathrm{m}$ followed by (f) drying of crystals by freeze drying.

\subsection{Lignin depolymerization}

BCD was carried out continuously in a plug flow reactor as previously described [26]. The lignin was fed at $5 \%(\mathrm{w} / \mathrm{w})$ in a $2.5 \% \mathrm{NaOH}$ solution with a flow rate of $20 \mathrm{~kg} / \mathrm{h}$. The reaction was carried out at $25.0 \mathrm{MPa}$ and $300{ }^{\circ} \mathrm{C}$. Liquid reaction products were continuously collected in an intermediate bulk container (IBC) and subsequently acidified with a $30 \% \mathrm{H}_{2} \mathrm{SO}_{4}$ solution at ambient temperature to a $\mathrm{pH}$ of 1.0. Oligomers precipitated and were removed from the aqueous solution by filtration using a filter press (HOLMAC Mod. H54.5/1.5). The filtrate was collected in a stainless steel IBC whereas the filter cake was washed several times with deionized water until nearly all salts were removed. The resulting BCD-oligomers were discharged and prepared for drying in a drying oven at $50{ }^{\circ} \mathrm{C}$ until a constant mass was reached. The filtrate containing BCD-oil (monomers and dimers) was extracted using a continuously operating, stirred extraction column (Pfaudler Normag Systems $\mathrm{GmbH}$ ) with methyl isobutyl ketone (MIBK) at ambient temperature. The MIBK-to-water ratio was $2: 1(\mathrm{w} / \mathrm{w})$, and the flow rate of MIBK was $30 \mathrm{~kg} / \mathrm{h}$. The light MIBK/BCD-oil phase was distilled during the ongoing extraction to remove the solvent, and the BCD-oil was vacuum dried at $40{ }^{\circ} \mathrm{C}$.

The yields of the obtained product fractions were calculated on the dry matter. The number average molecular weights $\left(M_{N}\right)$ and the average molecular weights $\left(M_{W}\right)$ of both fractions were determined by gel permeation chromatography (GPC) using a HPLC series 1260 (Agilent Technologies), equipped with GPC-columns (AppliChrom ABOA DMSOPhil-P Pore 250 \& 350) and an RID. The concentration of the phenolic monomers in the BCD-oil was quantified by gas chromatography mass spectrometry (Agilent GC 7890A and Agilent MSD 5975C) equipped with a HPMS5 capillary column (length $30 \mathrm{~m}$, inner diameter 0.25 $\mathrm{mm}$, film thickness $0.33 \mu \mathrm{m}$ ).

\subsection{Conceptual design and simulation}

The superstructure of the LCB converting beech wood to the relevant products, shown in Fig. 1, is divided in the following five sections: organosolv pulping, pulp bleaching, xylose valorization from $\mathrm{HH}$, malic acid fermentation, and basecatalyzed lignin depolymerization. For these sections, conceptual designs of process flowsheets were developed.

Process simulation using Aspen Plus was chosen as the appropriate method for the calculation of mass and energy balances, energy efficiencies, as well as sizing of the plant equipment. The input data of the process simulation are mainly from the experimental results, and other input data are indicated accordingly. Liquid activity coefficients were calculated with the NRTL (non-random two liquids) property method and Henry's law for dissolved gas in liquids for all unit operations. Only lignin depolymerization was simulated using the electrolyte NRTL thermodynamic package (included $\mathrm{NaOH}, \mathrm{H}_{2} \mathrm{SO}_{4}$, and their respective ions and salts) alongside with Henry's law to account for the non-condensable gasliquid equilibrium occurring during the BCD reactions [39]. All unit operations were simulated as continuous processes, which is a common simplification for conceptual studies [40-42]. Unit operations that would likely be operated in batch mode (e.g., malic acid fermentation) can thus be seen as an average mass and energy balance over time within the simulation.

It was assumed that the LCB is located in Germany on an existing chemical site, at which all required utilities and waste water treatment can be provided. The required utilities for the individual process stages are fired heat $(\mathrm{FH})$ with an inlet temperature of $1000{ }^{\circ} \mathrm{C}$, high pressure steam (HPS) at $2.2 \mathrm{MPa}$, medium pressure steam (MPS) at $0.9 \mathrm{MPa}$, low pressure steam (LPS) at $0.23 \mathrm{MPa}$, refrigerant (REF) with an inlet temperature of $-25^{\circ} \mathrm{C}$, cold/cool water $(\mathrm{CW})$ with an inlet temperature of $6{ }^{\circ} \mathrm{C} /$ $25^{\circ} \mathrm{C}$, and electricity (EE) for the power supply. A plant capacity to process 50,000 dry metric tonnes of beech wood annually and 8000 operating hours per year were assumed to be reasonable for a demonstration/pilot plant [43, 44].

\subsection{Costing and environmental assessment}

The mass and energy balances from the process simulation as well as the equipment lists from the conceptual design were used to conduct the costing and environmental assessments.

To estimate the economic competitiveness, the specific production costs were calculated according to a simplified approach in line with VDI guideline 6025 [45]. All relevant costs were allocated to the cost groups of capital-linked costs, consumption-linked costs, operation-linked costs, and other costs. Capital-linked costs were determined on the basis of equipment costs. The design, sizing, and determination of the quantity of the equipment were carried out in the process 
simulation. Equipment costs were estimated based on dimension and material according to the data and methodology described by Peters et al. [46] and Chauvel et al. [47]. The chemical plant cost index [48] and the Kölbel-Schulze index [49] were used as cost indices to update the costs to the base year 2017. Plant-specific surcharge factors were used to account for direct costs and indirect costs leading to fixed-capital investments. The annuity method was used to convert depreciation, interest, and maintenance into equal annual payments. Consumption-linked costs were based on usage and prices of raw materials, auxiliaries, process energy, and disposal costs. Operation-linked costs include estimations for labor costs. The labor costs were calculated by multiplying the number of employees with the annual labor costs per person. The number of employees typically needed in the chemical industry was estimated according to plant capacity, degree of automation, and a surcharge for supervision [46]. The annual labor costs consist of average salaries in the chemical industry in Germany $(60,000 € / a)$ [49] plus typical costs for social security contributions $(18.3 \%)$ and special payments (15\%). Other costs include administration, insurance, and uncertainties, which were calculated using surcharge rates. General assumptions for the costing are summarized in Table 2. The specific production costs were determined by dividing the total annual costs of production by the annual quantity of products.

For a more detailed costing, the production costs were calculated for each of the five sections of the LCB. The costs of the upstream organosolv process were allocated to the following three product streams: dissolving pulp, malic acid and BCDoligomers (Fig. 1) according to the mass flow of organic material with $50 \%, 34 \%$, and $16 \%$, respectively. Costs of the xylose valorization were completely allocated to the following malic acid fermentation process. Upstream costs were assigned to the following cost groups: capital-linked costs, consumption-linked costs, operation-linked costs, and other costs.

The mass and energy balances were used to calculate and compare the greenhouse gas (GHG) emissions of each LCB product. This life cycle assessment (LCA) was conducted according to ISO 14040 and 14044 standards. $\mathrm{CO}_{2}$ equivalents $\left(\mathrm{CO}_{2}\right.$-eq) were calculated as an indicator of the global warming potential with factors from the International Panel

Table 2. Main assumptions for costing

\begin{tabular}{lll}
\hline Parameter & Value & Unit \\
\hline Average cost of capital & 5.3 & $\%$ p.a. \\
Assessment period & 20 & Years \\
Maintenance, repairs & 2 & $\%$ of FCI p.a. \\
Administration & 20 & \% of operating costs p.a. \\
Insurance, uncertainties & 1.5 & \% of FCI p.a. \\
Annual labor costs & 80,000 & EUR/person \\
\hline
\end{tabular}

on Climate Change [50]. The $\mathrm{CO}_{2}$ emissions released during the disposal of the LCB products were considered to be climate-neutral assuming that they are part of the short-term carbon cycle [51]. The mass and energy balances were transferred to a life-cycle model using the Umberto LCA + 10.0.3 software [52]. For the organosolv process producing three intermediate products, the GHG emissions were allocated to each intermediate according to its share of organic content.

To estimate possible GHG savings, each LCB product was compared with a conventional reference product that would likely be substituted (Table 3). In case that an LCB product and its reference product are not chemically identical, a system expansion and a substitution ratio were used to compensate for different benefits [53]. To calculate GHG emissions of each reference product, the quantity according to the substitution ratio was multiplied with the emission factor of the reference product. The emission data for the auxiliary materials, energy carriers, and reference products are taken from the ecoinvent databases v.2.2 and v.3.4 $[54,55]$.

\section{Results and discussion}

\subsection{Organosolv pulping}

The composition and characteristics of the organosolv product streams cellulose fibers, lignin, and $\mathrm{HH}$ are dependent on factors, such as raw material quality (beech wood from sawmill or pulp mill), process parameters (temperature, residence time, $\mathrm{H}_{2} \mathrm{SO}_{4}$ use, heating regime, prehydrolysis), and type of lignin precipitation (dilution or distillation). The conditions used for the experiments, as presented in Section 2.1, are the results of detailed preliminary investigations optimizing these factors. It has been shown that fresh beech wood chips, provided by Lenzing AG (Austria), with an optimized chip geometry, a homogenous size distribution, and a high moisture content result in a better fiber quality. A low acid consumption of $0.8 \%$ $\mathrm{H}_{2} \mathrm{SO}_{4}$ per dry matter of wood proved to be suitable for stabilizing the hemicellulose and improving fiber properties. Moreover, the application of a mild prehydrolysis at $100{ }^{\circ} \mathrm{C}$ has also been found to increase the stability of hemicellulose. Nevertheless, to gain a good delignification, the reaction time was extended to $130 \mathrm{~min}$ at a pressure of $2.0 \mathrm{MPa}$ and $170{ }^{\circ} \mathrm{C}$.

The precipitation of lignin by the addition of two parts by mass of water, to decrease the ethanol concentration below the solubility limit of lignin, was replaced by a process for continuous lignin precipitation by evaporation of the solvent. As a result, large amounts of water were saved, and the sugar concentration in the $\mathrm{HH}$ increased by a factor of 11 .

The distribution of the lignocellulosic components cellulose, hemicellulose, and lignin in the organosolv component streams cellulose fibers, lignin, and liquid supernatant (which results in the $\mathrm{HH}$ after recovery of the solvents) is shown in 
Table 3. Reference products with emission factor [55], substitution ratio, and system expansion

\begin{tabular}{lllll}
\hline LCB product & Reference product & $\begin{array}{l}\text { Emission factor } \\
\left(\mathrm{kg} \mathrm{CO}_{2} \text {-eq/kg) }\right.\end{array}$ & Substitution ratio & System expansion \\
\hline Dissolving pulp & Pulp (sulfite process) & 1.21 & $1: 1$ & No SE \\
BCD-oligomers (in polyurethane) & Polyol (in polyurethane) & 4.32 & $1: 1$ & With SE \\
Malic acid & Citric acid & 3.09 & $1: 1.21$ & With SE \\
\hline
\end{tabular}

Fig. 2. As can be seen, high losses of hemicellulose occur at the reaction conditions. This can be attributed to the degradation of $\mathrm{HH}$ to oligomeric sugars, monomeric sugars, furans, carboxylic acids, and other extractives.

\subsection{Pulp bleaching}

With the presented bleaching sequence, it was possible to meet the requirements for dissolving pulp. This is remarkable, as the organosolv beech pulp had a high initial kappa number. Results of the single bleaching steps are presented in Table 4. By achieving a low hemicellulose content of $2 \%$, cold caustic extraction can be considered as an effective method for hemicellulose extraction from pulp. However, the process requires a high amount of $\mathrm{NaOH}$, which can be problematic in terms of costs and environmental impact. Increasing viscosity can be explained by the extraction of low-viscosity short-chain cellulose. The reduction in the kappa number from 28.6 to 5.6 using $5 \% \mathrm{NaOH}$ indicates that oxygen delignification is very effective. In addition, an increase in the degree of brightness in the pulp can be detected too. The viscosity does not change, due to the addition of $\mathrm{MgSO}_{4}$ [56]. The high yield-losses in both process steps may be due to the fact that at high alkali concentration cellulose is partially dissolved and further washed out [57]. During chlorine dioxide bleaching, the kappa number was lowered to 0.7 whereas a high degree of brightness was obtained. Despite relatively mild conditions in this process step, there is a significant loss of viscosity too. The relatively low consumption of $\mathrm{ClO}_{2}$ of $84.9 \%$ can be attributed to a nonuniform mixing of the chemical into the pulp. In the last bleaching step, hydrogen peroxide bleaching, a kappa number of 0.4 , and a degree of brightness of $93.9 \%$ were reached without a loss of viscosity. The rise in hemicellulose content compared to the chlorine dioxide stage can be explained by the ongoing delignification, whereby the relative amount of hemicellulose increases. The low $\mathrm{H}_{2} \mathrm{O}_{2}$ consumption indicates that the use of EDTA during chlorine dioxide bleaching has led to a removal of heavy metals from the pulp and thus no significant decomposition of $\mathrm{H}_{2} \mathrm{O}_{2}$ by heavy metals occurred.

Full bleaching could be realized with a reasonable charge of bleaching chemicals because the organosolv pulp responded extremely well to the oxygen delignification stage. The main weakness of the bleaching procedure was the high $\mathrm{NaOH}$ charge in the cold caustic extraction which was necessary to achieve the required low hemicellulose content. The pulp produced had a sufficient degree of brightness and a low hemicellulose content. Compared to literature specifications, the kappa number is slightly too high and the viscosity is only slightly within the specified limits [58]. A more extensive chlorine dioxide bleaching could lower the kappa number with little viscosity losses.

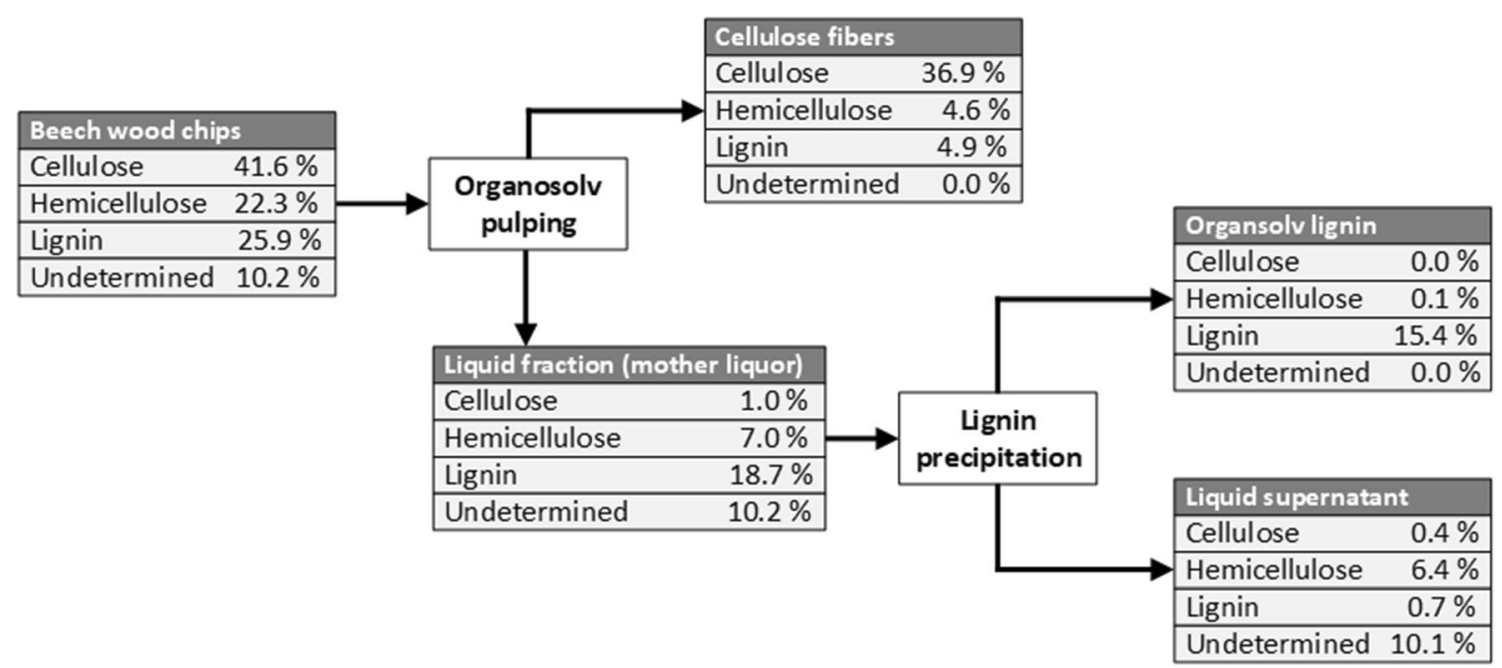

Fig. 2. Distribution of the cellulose, hemicellulose, and lignin in the organosolv component streams cellulose fibers, organosolv lignin, and liquid supernatant 
Table 4. Effect of the investigated bleaching sequence on the properties of organosolv pulp

\begin{tabular}{|c|c|c|c|c|c|c|c|c|}
\hline Bleaching step & $\begin{array}{l}\mathrm{pH}_{\text {in }} \\
(-)\end{array}$ & $\begin{array}{l}\mathrm{pH}_{\text {out }} \\
(-)\end{array}$ & $\begin{array}{l}\text { Chemical } \\
\text { consumption } \\
(\%)\end{array}$ & Cellulose yield (\%) & $\begin{array}{l}\text { Degree of brightness } \\
(\% \text { ISO })\end{array}$ & Kappa number (-) & $\begin{array}{l}\text { Intrinsic } \\
\text { viscosity } \\
(\mathrm{mL} / \mathrm{g})\end{array}$ & $\begin{array}{l}\text { Hemicellulose } \\
\text { content } \\
(\%)\end{array}$ \\
\hline Screening & - & - & - & 93.1 & 20.8 & 54.0 & 760 & - \\
\hline Cold caustic extr. & 13.0 & 13.0 & - & 89.3 & 21.6 & 28.6 & 780 & 2.0 \\
\hline $\mathrm{O}_{2}$ delignification & 12.7 & 11.5 & - & 94.4 & 57.1 & 5.6 & 650 & 2.0 \\
\hline $\mathrm{ClO}_{2}$ bleaching & 6.7 & 2.6 & 84.9 & 99.4 & 88.7 & 0.7 & 580 & 1.7 \\
\hline $\mathrm{H}_{2} \mathrm{O}_{2}$ bleaching & 11.4 & 11.0 & 16.1 & 99.8 & 93.9 & 0.4 & 560 & 1.9 \\
\hline
\end{tabular}

\subsection{Xylose valorization from hemicellulose}

The adsorption of HH with SEPABEADS SP700 resulted in the removal of $94.8 \%$ of lignin and other phenolic compounds. The simultaneous losses of hemicellulose, including oligomeric and monomeric xylose, amounted to $8.0 \%$. The adsorption behavior of both lignin and hemicellulose sugar in the multi-component solution is best described by the extended Freundlich isotherm. Hence, multilayer adsorption, with non-uniform distribution of adsorption heat and affinities, seems to be predominant [37].

Figure 3 shows the altered concentrations of oligomeric xylose, monomeric xylose, and furfural versus residence time in the continuous tube reactor at 160,180 , and $200{ }^{\circ} \mathrm{C}$ during the hydrothermal treatment of $\mathrm{HH}$. The conversion of the oligomeric xylose takes place in the following three steps: (a) hydrolysis of the oligomeric xylose to monomeric xylose, (b) dehydration of the monomeric xylose to furfural, and (c) degradation/condensation of furfural to insoluble humic substances and other hydrocarbons [59]. As can be seen in Fig. 3, a rapid hydrolytic cleavage of the oligomeric xylose takes

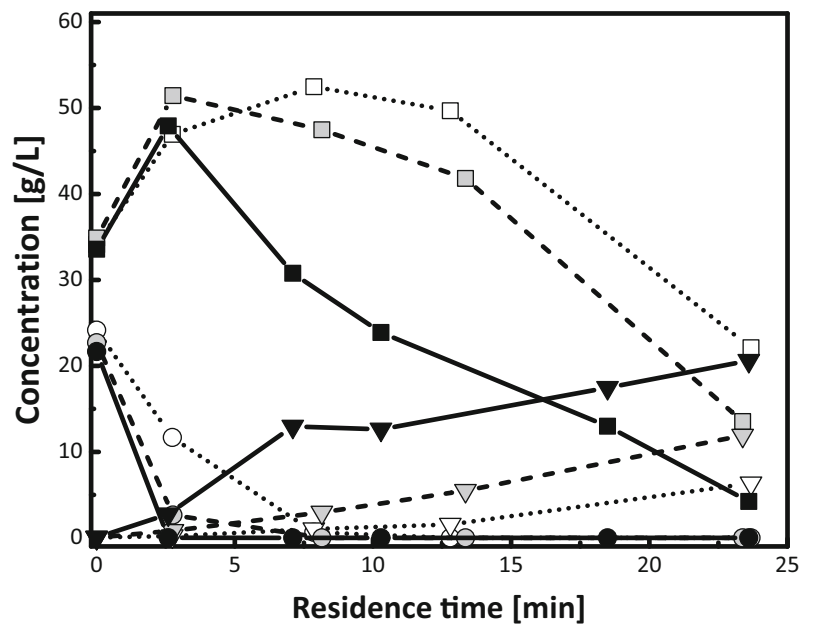

O Oligo-Xylose $\square$ Xylose $\nabla$ Furfural $\cdots 160^{\circ} \mathrm{C}---180^{\circ} \mathrm{C}-200^{\circ} \mathrm{C}$

Fig. 3. Concentration curve of oligo-xylose, xylose, and furfural during hydrothermal conversion in a continuous tube reactor place, which leads to a rapid increase in monomeric xylose concentration. The higher the process temperature, the faster the hydrolysis. As a result, the maximum monomeric xylose concentration is shifted to shorter residence times with increasing temperature. On the basis of the experimental data determined by Köchermann et al. [12], appropriate process parameters were identified in terms of maximum monomeric xylose yield, minimum oligomeric xylose concentration, minimum furfural concentration, and reduction of residence time. At reaction conditions of $180{ }^{\circ} \mathrm{C}$ and a residence time of 2.8 min, the above-mentioned criteria can be best met.

Appropriate process parameters for the NF of the hydrothermally treated $\mathrm{HH}$ were found to be a transmembrane pressure of 3.0 MPa, a temperature of $35{ }^{\circ} \mathrm{C}$, and a crossflow velocity of $1.1 \mathrm{~m} / \mathrm{s}$. Thus, obtaining a permeate flux of 38.2 $\mathrm{L} /\left(\mathrm{m}^{2} \mathrm{~h}\right)$ and observed component retentions of $100 \%$ for oligomeric xylose, $98.9 \%$ for glucose, $96.2 \%$ for monomeric xylose, $29.6 \%$ for $5-\mathrm{HMF}, 19.7 \%$ for furfural, and $3.7 \%$ for acetic acid. At the determined parameters, the hydrothermally treated $\mathrm{HH}$ was concentrated by NF to a volume reduction of 0.6 , meaning $60 \%$ of the feed solution was transferred into the NF permeate. Thereby, a monomeric xylose concentration of $126 \mathrm{~g} / \mathrm{L}$ in the retentate and a reduction of the inhibitor-toxylose ratio by $52 \%$ were achieved (Table 1 ).

\subsection{Malic acid fermentation}

Malic acid was successfully fermented on $\mathrm{HH}$ from the organosolv process. The oligomeric xylose present in high quantities next to monomeric xylose can be converted to malic acid with identical product formation rates compared to the utilization of technical xylose as feedstock. However, the substrate fraction could not be completely replaced by xylose from hemicellulose (only up to $40 \%$ (w/v)) since growth and metabolism were completely inhibited at higher concentrations by the contained inhibitors. The use of $\mathrm{HH}$ led to a lag phase at the beginning of cultivation when, among others, 5HMF was degraded by the fungi. With increased concentration of hemicellulose, the metabolism shifted to succinic acid 
production, which reduced the malic acid yield. Overall, the yield of malic acid obtained with $\mathrm{HH}$ was still higher than with technical xylose (43\%-105\% higher) due to the wider substrate spectrum. As a result of $\mathrm{HH}$ pretreatment by precipitation, adsorption, and extraction, some of the inhibitors could be removed and the lag phase was shortened.

The fermentative malic acid production from xylose by Aspergillus oryzae was successfully transferred from the laboratory- $(0.1 \mathrm{~L})$ to the pilot-scale $(1000 \mathrm{~L})$. The EDCF was used as the scale-up criterion resulting in a similar pellet morphology of the fungi. A yield of $0.63 \mathrm{~mol}$ malic acid per mol xylose and an average product formation rate of 0.15 $\mathrm{g} /(\mathrm{Lh})$ could be achieved. A first strategy for the downstream processing of malic acid from the fermentation broth was developed and demonstrated on a pilot scale: consisting of acidification, thermal inactivation, biomass separation by filtration, and purification by cooling crystallization and drying, to obtain the target product. The concentration of the fermentation product malic acid, the by-products succinic acid and fumaric acid, and the starting material xylose, as well as the liquid-phase volume of the piloted fermentation process and the separation and purification cascade, are displayed in Fig. 4. The best yield and purity in cooling crystallization was achieved with a $\mathrm{pH}$ of 3.3 and a cooling rate of $5{ }^{\circ} \mathrm{C} / \mathrm{h}$. However, the amount of malic acid remaining dissolved in the filtrate after crystallization as well as a non-optimized biomass separation and dewatering resulted in a high overall product loss. A malic acid quantity of approx. $15 \mathrm{~kg}(29 \%$ yield) with a purity of $84 \%$ was produced.

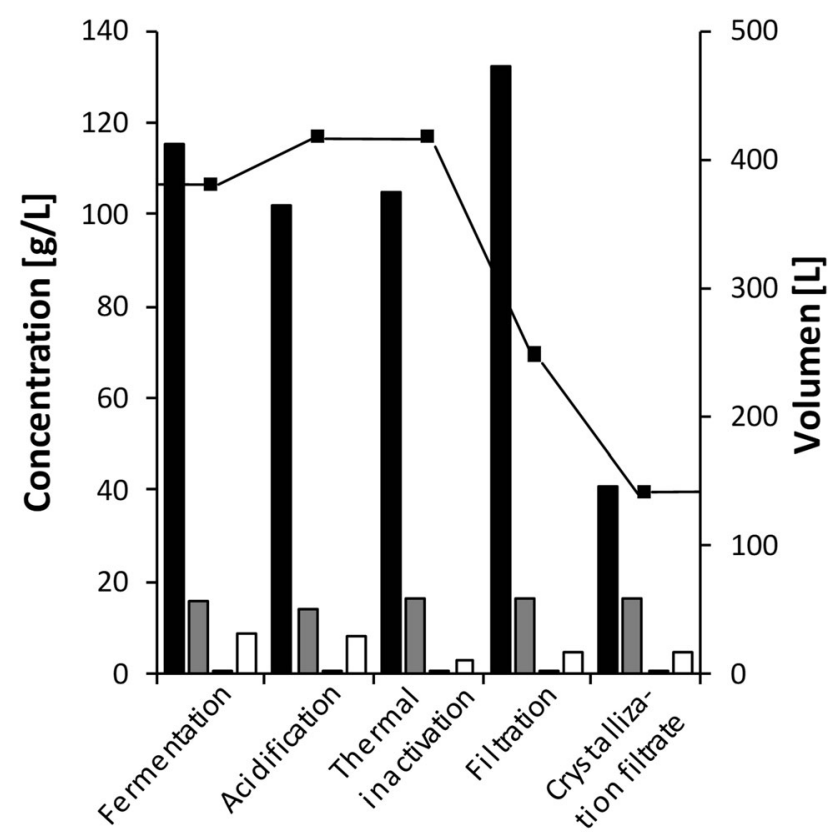

- Malic acid $\square$ Succinic acid $\square$ Fumaric acid $\square$ Xylose - -Volumen

Fig. 4. Concentration of malic acid, succinic acid, fumaric acid, and xylose as well as the liquid phase volume of the piloted fermentation process and the separation and purification cascade

\subsection{Lignin depolymerization}

Cleavage of lignin via $\mathrm{BCD}$ and subsequent separation resulted in solid BCD-oligomers, a liquid BCD-oil, small organic compounds, and gasses (Table 5). The lignin fragments of the $\mathrm{BCD}$-oligomers were obtained with a depolymerization degree of at least $35 \%$ relative to the starting material. The $\mathrm{BCD}$-oil is a fraction containing liquid phenolic monomers and dimers. They were isolated by liquid-liquid extraction of the product solution after solid-liquid separation of the BCD-oligomers. The main monomeric components identified in the BCD-oil were syringol, guaiacol, catechol, vanillin, and phenol. However, their content in the oily phase was low $(\leq 3 \%)$. Small organic compounds formed by cleavage of methoxy and ethoxy moieties from the lignin molecules were mainly methanol, ethanol, and their corresponding acids. Formed gasses were mainly $\mathrm{CH}_{4}$ and $\mathrm{CO}_{2}$.

As described in Section 2.5, the reference for the design of the BCD-process and the mass and energy balances is the cleavage using $5 \%(\mathrm{w} / \mathrm{w})$ lignin in a total mass flow of 20 $\mathrm{kg} / \mathrm{h}$, achieving a conversion rate of $94.5 \%$. The relatively mild reaction conditions of $25.0 \mathrm{MPa}$ and a temperature of $300{ }^{\circ} \mathrm{C}$ lead to a depolymerization with good yields of $\mathrm{BCD}$-oil while avoiding repolymerization of the formed lignin fragments [27]. This is necessary to reproducibly obtain the required product specifications and to provide a stable, continuous process.

\subsection{Costing and environmental assessment}

Costing and environmental assessment of the entire LCB presented in Fig. 1 was conducted. As part of a preliminary assessment of the single-process steps, it was found that liquidliquid extraction and subsequent purification of the BCD-oil during lignin depolymerization is not beneficial. In particular, it has been shown that MIBK as a solvent has a considerable negative influence on the costing and environmental impact of the process. Therefore, an alternative approach for assessing the process excluded $\mathrm{BCD}$-oil as a value-determining product and focused exclusively on BCD-oligomers. Hence, the products of the LCB were dissolving pulp, phenolic BCD-oligomers, and malic acid. The results of the assessment include the mass and energy balance from process simulation with Aspen Plus, the economic analysis by determination of production costs, and the environmental analysis using LCA.

\subsubsection{Mass and energy balances}

The main input and output mass streams of the LCB processing 50,000 dry metric tonnes of beech wood annually are presented in Table 6. It should be mentioned that the examinations carried out in this section have a conceptual character and are based on the experimental work from Section 3.1 to 
Table 5. Product fractions and corresponding molecular mass as well as composition after the cleavage of lignin via base-catalyzed depolymerization (BCD)

\begin{tabular}{lllll}
\hline & BCD-oligomers & BCD-oil & Gasses & Small organic compounds \\
\hline Product fraction (\% to lignin used) & 67.5 & 11.0 & 3.7 & 12.3 \\
$M_{N}(\mathrm{~g} / \mathrm{mol})$ & 588 & 127 & - & - \\
$M_{W}(\mathrm{~g} / \mathrm{mol})$ & 1403 & 283 & - & - \\
Composition (\% to lignin used) & - & $1.8 \%$ Syringol, $0.9 \%$ guaiacol, $0.2 \%$ & $\mathrm{CH}_{4}, \mathrm{CO}_{2}$ & Methanol, ethanol, \\
& & catechol, $0.1 \%$ vanillin, $0.01 \%$ phenol & formic acid, acetic acid \\
\hline
\end{tabular}

Section 3.5. The conversion rates of the starting materials to products, which are described in the individual process stages subsequently, refer to the dry matter of the respective components, meaning water content $(\mathrm{w})$ is $0 \%$.

During organosolv pulping, $46.4 \%$ of the beech wood is converted to cellulose fibers, $15.2 \%$ to lignin, and $15.7 \%$ to hemicellulose sugars (oligomeric and monomeric xylose) in the HH. This process stage is characterized by a high water demand, as water is used in large quantities as a solvent and as wash water for cellulose fibers and lignin. A further reduction of the necessary amount of water has great potential for optimizing the process, due to lower energy requirements and easier access to the hemicellulose sugar. The high water consumption also results in a high waste water load of $13.4 \mathrm{~m}^{3}$ per metric tonne of raw fibers $(\mathrm{w}=0 \%)$. Due to an efficient ethanol recovery with a rate of $99.3 \%$, the ethanol demand can be reduced to $0.21 \mathrm{t} / \mathrm{h}$. During pulp bleaching, $63.0 \%$ of the raw fibers is converted to dissolving pulp. In this process stage, water is by far the largest mass flow, where it is used for the dilution of the pulp during pulp screening and cold caustic extraction as well as for the pulp washing in the oxygen delignification, chlorine dioxide bleaching, and hydrogen peroxide bleaching. Due to the high water demand, recirculation is essential, and in this study, it was assumed that $11 \mathrm{~m}^{3}$ of waste water per metric tonne of dissolving pulp arise [60]. The consumption of chemicals, especially of $\mathrm{NaOH}(1.34 \mathrm{t} / \mathrm{h}$ in the cold caustic extraction) is also very high. A recirculation strategy for these components was not developed but is also considered necessary. Reasons for not developing concepts for recirculation are the lack of information about possible recovery rates and a lack of experimental capacities within the scope of these investigations. During the xylose valorization from hemicellulose, $90 \%$ of the oligomeric xylose in the $\mathrm{HH}$ is converted to monomeric xylose. The advantage of this process stage is the low requirement of further input streams, such as water and other chemicals. A periodic renewal of adsorption material and membranes (lifetime 1.5 years [61]) is included in the costing. For the desorption of lignin from the polymeric sorbents, $2.36 \mathrm{t} / \mathrm{h}$ ethanol is needed [62], which can be recovered with a rate of $99.5 \%$. The required amount of fresh ethanol is thus only $0.01 \mathrm{t} / \mathrm{h}$. For each metric tonne of monomeric xylose $(\mathrm{w}=0 \%), 39.5 \mathrm{~m}^{3}$ of waste water is produced. This is a considerable quantity, mainly due to the large water input within the organosolv pulping, and should be reduced. During the malic acid fermentation, $58.0 \%$ of the xylose is processed to malic acid. This comparatively low yield is attributed to the formation of by-products, such as succinic acid and fumaric acid, and to the high losses of malic acid during the purification processes. Process water is used for the dilution of the xylose solution during the cultivation of the microorganisms and the preparation of a $70 \% \mathrm{H}_{3} \mathrm{PO}_{4}$ solution. For the buffering of the fermentation process and the subsequent acidification of the fermentation broth, a considerable amount of $\mathrm{CaCO}_{3}$ or $\mathrm{H}_{3} \mathrm{PO}_{4}$ is required. The waste water load is $11.2 \mathrm{~m}^{3}$ per metric tonne of malic acid $(\mathrm{w}=0 \%)$. During the lignin depolymerization, $67.5 \%$ of the lignin is converted to $\mathrm{BCD}$-oligomers. Large amounts of water, $\mathrm{H}_{2} \mathrm{SO}_{4}$, and $\mathrm{NaOH}$ are consumed in this process stage. The demand for water is mainly due to the washing of the BCD-oligomers (53.9\%) as well as for the preparation of the $2.5 \% \mathrm{NaOH}$ solution (33.4\%) and the $30 \% \mathrm{H}_{2} \mathrm{SO}_{4}$ solution (4.7\%). With a reduction in the necessary amount of water and chemicals, the waste water load of $86.2 \mathrm{~m}^{3}$ per metric tonne of $\mathrm{BCD}$-oligomers $(\mathrm{w}=0 \%$ ), as well as its contamination with salts and organic matter, could be reduced.

Energy requirements and utility consumption of the studied LCB are shown in Table 7. The total energy requirements of the individual utilities decrease in the following order: MPS with 14.5 MW, CW with 9.0 MW, HPS with 5.8 MW, LPS with 4.9 MW, EE with 3.1 MW, FH with 2.6 MW, and REF with $0.4 \mathrm{MW}$. Within the organosolv pulping, the pulping reactor requires the entire HPS and the drying of lignin the entire MPS. The ethanol recovery within the organosolv pulping requires the whole LPS and CW. In the pulp bleaching, the highest utility demand is the MPS for drying the dissolving pulp, followed by the EE for mixing the reagents and the LPS for heating the bleaching reactions. The highest energy demands in the process stage $x y$ lose valorization from hemicellulose are caused by the recovery of ethanol from the desorption solution requiring most of the LPS and $\mathrm{CW}$. The HPS is consumed during the hydrothermal process and EE for the membrane filtration. The malic acid fermentation requires the lowest temperature in the process 
Table 6. Mass balance, energy efficiency, emission factors, and (production) costs of the lignocellulose biorefinery concept (products and production costs are shown in bold) ${ }^{\mathrm{a}}[46] ;{ }^{\mathrm{b}}[63] ;{ }^{\mathrm{c}}[64] ;{ }^{\mathrm{d}}[65] ;{ }^{\mathrm{e}}[66] ;{ }^{\mathrm{f}}[67] ;{ }^{\mathrm{g}}[1] ;{ }^{\mathrm{h}}[2] ;{ }^{\mathrm{i}}[68] ;{ }^{\mathrm{j}}[69] ;{ }^{\mathrm{k}}[70] ;{ }^{\mathrm{l}}[71] ;{ }^{\mathrm{m}}[72] ;{ }^{\mathrm{n}}[73] ;{ }^{\mathrm{o}}[74] ;{ }^{\mathrm{p}}[75] ;{ }^{\mathrm{x}}$ assumption; ${ }^{\mathrm{H}}$ calculated

\begin{tabular}{|c|c|c|c|c|c|}
\hline Process stage and main streams & $\begin{array}{l}\text { Mass input } \\
(\mathrm{t} / \mathrm{h})\end{array}$ & $\begin{array}{l}\text { Mass output } \\
(\mathrm{t} / \mathrm{h})\end{array}$ & $\begin{array}{l}\text { Energy } \\
\text { efficiency } \\
(\%)\end{array}$ & $\begin{array}{l}\text { Emission factors } \\
\left(\mathrm{kg} \mathrm{CO}_{2}-\mathrm{eq} / \mathrm{kg}\right)\end{array}$ & $\begin{array}{l}\text { (Production) } \\
\text { costs } \\
(\mathrm{EUR} / \mathrm{t})\end{array}$ \\
\hline \multicolumn{6}{|l|}{ Organosolv pulping } \\
\hline Process water & 68.2 & 0 & & 0.0004 & $0.16^{\mathrm{a}, \mathrm{b}}$ \\
\hline Beech wood $(\mathrm{w}=50 \%)$ & 12.5 (38.7 MW) & 0 & & - & $50^{\mathrm{c}}$ \\
\hline Ethanol & 0.21 & 0 & & 0.41 & $550^{\mathrm{d}}$ \\
\hline $\mathrm{H}_{2} \mathrm{SO}_{4}$ & 0.06 & 0 & & 0.12 & $70^{\mathrm{e}, \mathrm{f}}$ \\
\hline Waste water & 0 & 38.1 & & 0.0004 & $2.5^{\mathrm{g}, \mathrm{h}}$ \\
\hline Hemicellulose hydrolysate & 0 & 32.3 & & 0.01 & - \\
\hline Cellulose fibers $(\mathrm{w}=70 \%)$ & 0 & 9.67 & & 0.04 & - \\
\hline Lignin $(\mathrm{w}=2 \%)$ & 0 & 0.97 & & 0.13 & - \\
\hline \multicolumn{6}{|l|}{ Pulp bleaching } \\
\hline Process water & 14.3 & 0 & & 0.004 & $0.16^{\mathrm{a}, \mathrm{b}}$ \\
\hline Cellulose fibers $(\mathrm{w}=70 \%)$ & 9.67 & 0 & & 0.04 & - \\
\hline $\mathrm{NaOH}$ & 1.47 & 0 & & 1.35 & $600^{\mathrm{i}, \mathrm{j}}$ \\
\hline $\mathrm{O}_{2}$ & 0.05 & 0 & & 0.63 & $50^{\mathrm{k}}$ \\
\hline $\mathrm{ClO}_{2}$ & 0.04 & 0 & & 5.14 & $1500^{\mathrm{x}}$ \\
\hline $\mathrm{H}_{2} \mathrm{O}_{2}$ & 0.02 & 0 & & 1.45 & $300^{1}$ \\
\hline $\mathrm{MgSO}_{4}$ & 0.01 & 0 & & 0.25 & $200^{\mathrm{x}}$ \\
\hline EDTA & 0.01 & 0 & & 4.03 & $2000^{\mathrm{x}}$ \\
\hline Waste water & 0 & 22.5 & & 0.004 & $2.5^{\mathrm{g}, \mathrm{h}}$ \\
\hline Dissolving pulp $(\mathrm{w}=10 \%)$ & 0 & $2.03(8.12 \mathrm{MW})$ & 21.0 & 1.62 & $1350^{\#}$ \\
\hline Shiver $(\mathrm{w}=60 \%)$ & 0 & 0.97 & & - & - \\
\hline Exhaust gas & 0 & 0.06 & & - & - \\
\hline \multicolumn{6}{|l|}{ Xylose valorization } \\
\hline Hemicellulose hydrolysate & 32.3 & 0 & & 0.01 & - \\
\hline Process water & 1.87 & 0 & & 0.004 & $0.16^{\mathrm{a}, \mathrm{b}}$ \\
\hline $\mathrm{NaOH}$ & 0.03 & 0 & & 1.35 & $600^{\mathrm{i}, \mathrm{j}}$ \\
\hline Ethanol & 0.01 & 0 & & 0.41 & $550^{\mathrm{d}}$ \\
\hline Waste water & 0 & 31.6 & & 0.004 & $2.5^{\mathrm{g}, \mathrm{h}}$ \\
\hline Xylose solution $\left(c_{\text {Xylose }}=360 \mathrm{~g} / \mathrm{l}\right)$ & 0 & 2.47 & & 0.42 & - \\
\hline Suspended solids $(\mathrm{w}=60 \%)$ & 0 & 0.15 & & - & - \\
\hline \multicolumn{6}{|l|}{ Malic acid fermentation } \\
\hline Process water & 4.59 & 0 & & 0.004 & $0.16^{\mathrm{a}, \mathrm{b}}$ \\
\hline Xylose solution $\left(c_{\text {Xylose }}=360 \mathrm{~g} / \mathrm{l}\right)$ & 2.47 & 0 & & 0.42 & - \\
\hline $\mathrm{CaCO}_{3}$ & 0.67 & 0 & & 0.01 & $100^{\mathrm{x}}$ \\
\hline $\mathrm{H}_{3} \mathrm{PO}_{4}$ & 0.39 & 0 & & 1.5 & $600^{\mathrm{n}, \mathrm{o}}$ \\
\hline Nutrients & 0.03 & 0 & & 2.12 & $460^{\mathrm{x}}$ \\
\hline Air & 0.01 & 0 & & - & - \\
\hline $\mathrm{N}_{2}$ & 0.01 & 0 & & 0.25 & $50^{\mathrm{p}}$ \\
\hline Waste water & 0 & 5.39 & & 0.004 & $2.5^{\mathrm{g}, \mathrm{h}}$ \\
\hline Biomass $+\mathrm{Ca}_{3}\left(\mathrm{PO}_{4}\right)_{2}(\mathrm{w}=60 \%)$ & 0 & 1.98 & & - & - \\
\hline Malic acid $(w=2 \%)$ & 0 & $0.52(1.45 \mathrm{MW})$ & 3.7 & 3.09 & $4750^{\#}$ \\
\hline Exhaust gas & 0 & 0.28 & & - & - \\
\hline \multicolumn{6}{|l|}{ Lignin depolymerization } \\
\hline Process water & 53.8 & 0 & & 0.004 & $0.16^{\mathrm{a}, \mathrm{b}}$ \\
\hline Lignin $(\mathrm{w}=2 \%)$ & 0.97 & 0 & & 0.13 & - \\
\hline $\mathrm{H}_{2} \mathrm{SO}_{4}$ & 1.08 & 0 & & 0.12 & $70^{\mathrm{m}}$ \\
\hline $\mathrm{NaOH}$ & 0.46 & 0 & & 1.35 & $600^{\mathrm{i}, \mathrm{j}}$ \\
\hline Air & 0.09 & 0 & & - & - \\
\hline Waste water & 0 & 55.6 & & 0.004 & $2.5^{\mathrm{g}, \mathrm{h}}$ \\
\hline BCD-oligomers $(w=2 \%)$ & 0 & $0.66(6.04 \mathrm{MW})$ & 15.6 & 2.04 & $2180^{\#}$ \\
\hline Exhaust gas & 0 & 0.12 & & - & - \\
\hline
\end{tabular}



MPS, which is the highest energy demand of the process step, is used for the heat sterilization of the fermentation broth and for drying the malic acid crystals. The lignin depolymerization requires the highest temperature in the process, where it was assumed that the BCD-reactor is heated to $300{ }^{\circ} \mathrm{C}$ using $\mathrm{FH}$. The $\mathrm{CW}$ is used for cooling down the highly exothermic reaction when preparing the $30 \% \mathrm{H}_{2} \mathrm{SO}_{4}$ solution for $\mathrm{BCD}$ oligomer precipitation, and MPS is used for the drying of the BCD-oligomers.

The energy efficiency for the beech-wood-to-product conversion is defined as the energy output in the products divided by the energy input, including raw material and the electrical power requirements. The calculations are based on the following estimations: (a) lower heating values of the raw materials and the products were obtained from Aspen Plus and (b) electrical energy is provided by a natural gas fired combined heat and power plant with an electrical efficiency of 58\% [4]. The energy efficiency for the primary products dissolving pulp and BCD-oligomers is $21.0 \%$ and $15.6 \%$, respectively, and for the secondary product malic acid 3.7\% (Table 6). Hence, the overall energy efficiency of the LCB is $40.3 \%$. Compared with that in other literature [4, 41], the energy efficiency of the studied concept is low. An increase in energy efficiency could be achieved by an efficient recovery of all components which arise during the lignin depolymerization (e.g., phenolic monomers and dimers), by optimizing the recovery of malic acid from the fermentation broth and/or by the conversion of the monomeric xylose to other products. It must be considered, however, that most of the processes studied were tested here for the first time at a pilot scale and that a comprehensive optimization has not yet taken place.

\subsubsection{Costing and environmental performance}

Investment and annual costs for the individual process steps in the LCB are summarized in Table 8. Organosolv pulping has the largest share $(28 \%)$ of the total investment, before malic acid fermentation (22\%), based-catalyzed lignin

Table 7. Energy/utility requirements, emission factors, and costs of the lignocellulose biorefinery concept $(O P$ organosolv pulping, $P B$ pulp bleaching, $X V$ xylose valorization, $M A F$ malic acid fermentation, $L D$ for the crystallization, which is cooled to $0{ }^{\circ} \mathrm{C}$ using REF.

depolymerization (20\%), pulp bleaching (16\%), and xylose valorization from hemicellulose $(14 \%)$. The main drivers regarding the annual costs are consumption-linked costs, in particular for beech wood during pulping and auxiliaries as well as operating materials for the other processes.

The specific production costs (Table 9) for dissolving pulp and BCD-oligomers are close to market prices on the basis of the assumptions made. The costs for malic acid production are significantly higher than the market price and are currently not competitive. The specific production costs of the three products show a similar cost distribution: Consumption-linked costs account for the largest share (49\%-66\%), followed by capitallinked costs $(16 \%-26 \%)$, operation-linked costs (12\%-16\%), and other costs $(5 \%-8 \%)$. The highest cost factors of the individual processes in the percentage of production costs were $\mathrm{NaOH}$ for pulp bleaching (32\%) and lignin depolymerization (20\%) and phosphoric acid for malic acid fermentation (13\%). When assessing the results, it should be noted that, unlike market prices, the cost of production does not include taxes or distribution costs.

Implementing the LCB in the market and substituting the conventional reference products would contribute to a mitigation of global warming. The production of $\mathrm{BCD}$-oligomers and malic acid within the LCB would each cause lower GHG emissions than their corresponding reference products as can be seen in Fig. 5. However, the GHG emissions of pulp production are higher than those of the reference pulp production in the sulfite process. The main reasons for that are a high consumption of $\mathrm{NaOH}$ and a relatively high emission factor of the $\mathrm{ClO}_{2}$ used for pulp bleaching. Within the biorefinery concept, the highest GHG saving is reached by the substitution of polyol with BCD-oligomers in PUR.

\section{Conclusion}

The aim of this study was to demonstrate and assess an integrated lignocellulose biorefinery (LCB), including the process

lignin depolymerization, $E E$ electricity, $R E F$ refrigerant, $C W$ cold/cool water, $L P S$ low pressure steam, MPS medium pressure steam, HPS high pressure steam, $F H$ fired heat) ${ }^{\mathrm{a}}[76] ;{ }^{\mathrm{b}}[46] ;{ }^{\mathrm{c}}[2] ;{ }^{\mathrm{d}}[77]$

\begin{tabular}{|c|c|c|c|c|c|c|c|c|}
\hline Process utility & $\begin{array}{l}\text { OP } \\
\text { (MW) }\end{array}$ & $\begin{array}{l}\text { PB } \\
\text { (MW) }\end{array}$ & $\begin{array}{l}\text { XV } \\
\text { (MW) }\end{array}$ & $\begin{array}{l}\text { MAF } \\
\text { (MW) }\end{array}$ & $\begin{array}{l}\text { LD } \\
\text { (MW) }\end{array}$ & $\begin{array}{l}\text { Total } \\
\text { (MW) }\end{array}$ & $\begin{array}{l}\text { Emission factor } \\
\left(\mathrm{kg} \mathrm{CO}_{2} \text {-eq/kWh }\right)\end{array}$ & Costs \\
\hline $\mathrm{EE}$ & 0.35 & 0.32 & 0.45 & 0.16 & 0.25 & 1.53 & 0.43 & $100 \mathrm{EUR} / \mathrm{MWh}^{\mathrm{a}}$ \\
\hline REF & 0.0 & 0.0 & 0.0 & 0.20 & 0.0 & 0.20 & - & 5.6 EUR/MWh ${ }^{\mathrm{b}}$ \\
\hline $\mathrm{CW}$ & 2.21 & 0.0 & 1.06 & 0.13 & 1.08 & 4.48 & - & $0.05 \mathrm{EUR} / \mathrm{t}^{\mathrm{a}, \mathrm{c}}$ \\
\hline LPS & 0.46 & 0.22 & 1.64 & 0.11 & 0.0 & 2.43 & 0.07 & $25 \mathrm{EUR} / \mathrm{t}^{\mathrm{c}}$ \\
\hline MPS & 3.60 & 2.21 & 0.0 & 0.86 & 0.58 & 7.25 & 0.07 & $25 \mathrm{EUR} / \mathrm{t}^{\mathrm{c}}$ \\
\hline HPS & 2.28 & 0.0 & 0.64 & 0.0 & 0.0 & 2.92 & 0.07 & $25 \mathrm{EUR} / \mathrm{t}^{\mathrm{c}}$ \\
\hline FH & 0.0 & 0.0 & 0.0 & 0.0 & 1.29 & 1.29 & 0.07 & $50 \mathrm{EUR} / \mathrm{MWh}^{\mathrm{d}}$ \\
\hline
\end{tabular}


Table 8. Investment and annual costs of the lignocellulose biorefinery

concept (summation of cost groups are shown in bold; $O P$ organosolv pulping, $P B$ pulp bleaching, $X V$ xylose valorization, $M A F$ malic acid fermentation, $L D$ lignin depolymerization)

\begin{tabular}{llrrrrr}
\hline & & \multicolumn{1}{l}{ OP } & \multicolumn{1}{c}{ PB } & XV & MAF & LD \\
\hline Investment sum & & & & \\
Capital-linked costs & $(\mathrm{kEUR})$ & $\mathbf{3 0 , 8 3 0}$ & $\mathbf{1 8 , 1 5 0}$ & $\mathbf{1 5 , 3 9 0}$ & $\mathbf{2 4 , 7 1 0}$ & $\mathbf{2 2 , 5 0 0}$ \\
Depreciation & $(\mathrm{kEUR} / \mathrm{a})$ & $\mathbf{3 1 4 0}$ & $\mathbf{1 8 7 0}$ & $\mathbf{1 5 8 0}$ & $\mathbf{2 5 3 0}$ & $\mathbf{2 3 2 0}$ \\
Interest & $(\mathrm{kEUR} / \mathrm{a})$ & 1540 & 910 & 770 & 1240 & 1130 \\
Maintenance & $(\mathrm{kEUR} / \mathrm{a})$ & 1000 & 600 & 500 & 800 & 740 \\
Consumption-linked costs & $(\mathrm{kEUR} / \mathrm{a})$ & 600 & 360 & 310 & 490 & 450 \\
Raw material & $(\mathrm{kEUR} / \mathrm{a})$ & $\mathbf{9 3 8 0}$ & $\mathbf{9 7 9 0}$ & $\mathbf{2 7 1 0}$ & $\mathbf{3 8 8 0}$ & $\mathbf{5 0 5 0}$ \\
Auxiliary and operating material & $(\mathrm{kEUR} / \mathrm{a})$ & 5000 & - & - & - & - \\
Energy supply & $(\mathrm{kEUR} / \mathrm{a})$ & 1140 & 7800 & 1090 & 3320 & 3000 \\
Disposal costs & $(\mathrm{kEUR} / \mathrm{a})$ & 2490 & 1540 & 970 & 450 & 940 \\
Operation-linked costs & $(\mathrm{kEUR} / \mathrm{a})$ & 750 & 450 & 650 & 110 & 1110 \\
Labor costs & $(\mathrm{kEUR} / \mathrm{a})$ & $\mathbf{2 3 0 0}$ & $\mathbf{1 6 6 0}$ & $\mathbf{1 2 9 0}$ & $\mathbf{1 1 0 0}$ & $\mathbf{1 0 0 0}$ \\
Other costs & $(\mathrm{kEUR} / \mathrm{a})$ & 2300 & 1660 & 1290 & 1100 & 1000 \\
Administration & $(\mathrm{kEUR} / \mathrm{a})$ & $\mathbf{1 0 9 0}$ & $\mathbf{6 0 0}$ & $\mathbf{5 5 0}$ & $\mathbf{6 9 0}$ & $\mathbf{5 4 0}$ \\
Insurance & $(\mathrm{kEUR} / \mathrm{a})$ & 640 & 330 & 320 & 320 & 200 \\
Uncertainties & $(\mathrm{kEUR} / \mathrm{a})$ & 300 & 180 & 150 & 250 & 230 \\
\hline & $(\mathrm{kEUR} / \mathrm{a})$ & 150 & 90 & 80 & 120 & 110 \\
\hline
\end{tabular}

steps of organosolv pulping, pulp bleaching, hydrothermal conversion of hemicellulose to xylose and its purification, malic acid fermentation, and the base-catalyzed lignin depolymerization. It was shown that beech wood can be converted in the following three products: dissolving pulp, phenolic BCD-oligomers, and malic acid. During organosolv pulping, $46.4 \%$ of the beech wood was converted to cellulose fibers, $15.7 \%$ to hemicellulose sugars (oligomeric and monomeric xylose) in the hemicellulose hydrolysate $(\mathrm{HH})$, and $15.2 \%$ to lignin. From the calculated mass and energy balance, it could be concluded that the implementation of a more efficient pulp washing unit can lead to a more effective delignification and a reduction in process water demand. The pulp bleaching sequence consisted of screening and washing, cold caustic extraction, oxygen delignification, chlorine dioxide bleaching, and hydrogen peroxide bleaching. In this sequence, a conversion of $63.0 \%$ of the cellulose fibers to dissolving pulp with a slightly too high kappa number was achieved. However, to reduce the environmental impact of the bleaching sequence, recirculation of process water and chemicals is crucial. Xylose valorization from hemicellulose was realized by connecting adsorption, hydrothermal treatment, and nanofiltration processes, resulting in $90 \%$ of the oligomeric xylose in the $\mathrm{HH}$ being converted to the monomer. During the subsequent malic acid fermentation, 58\% of the xylose was converted to malic acid. To achieve higher overall yields, the recovery and purification of malic acid must be further improved. During the base-catalyzed depolymerization (BCD) of lignin, 67.5\% was converted to oligomers and $11 \%$ to smaller aromatic compounds (BCD-oil). This process should be further optimized in terms of the reduction or the recovery of $\mathrm{NaOH}$ to reduce costs and environmental impact. By integrating and optimizing the single process steps into an LCB, the TRL could be increased to 5 .

The overall energy efficiency of the LCB, based on the findings of the demonstration studies and simulated with Aspen Plus, was $40.3 \%$. This is mainly due to material losses during lignin depolymerization and malic acid fermentation. Production costs for dissolving pulp (1350 €/t) and BCD-

Table 9. Product costs of the lignocellulose biorefinery concept (resulting production costs are shown in bold) ${ }^{\mathrm{a}}[78] ;{ }^{\mathrm{b}}[79] ;{ }^{\mathrm{c}}[80] ;{ }^{\mathrm{d}}[81]$

\begin{tabular}{lllll}
\hline & & $\begin{array}{l}\text { Dissolving pulp } \\
(\mathrm{w}=10 \%)\end{array}$ & $\begin{array}{l}\text { Malic acid } \\
(\mathrm{w}=2 \%)\end{array}$ \\
\hline Capital-linked costs & (EUR/t product) & 213 & 1248 & $\begin{array}{l}\text { BCD-oligomers } \\
(\mathrm{w}=2 \%)\end{array}$ \\
Consumption-linked costs & (EUR/t product) & 892 & 2350 & 537 \\
Operation-linked costs & (EUR/t product) & 173 & 764 & 1243 \\
Other costs & (EUR/t product) & 72 & 388 & 264 \\
Production costs & (EUR/t product) & $\mathbf{1 3 5 0}$ & $\mathbf{4 7 5 0}$ & $\mathbf{2 1 3 6}$ \\
Price of reference products & (EUR/t product) & $1440^{\mathrm{a}}$ & $2000^{\mathrm{c}, \mathrm{d}}$ & $2000^{\mathrm{b}}$ \\
\hline
\end{tabular}




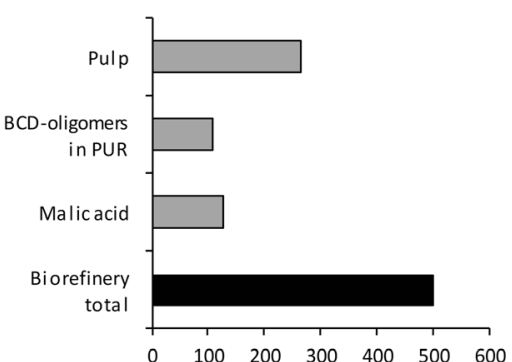

a)

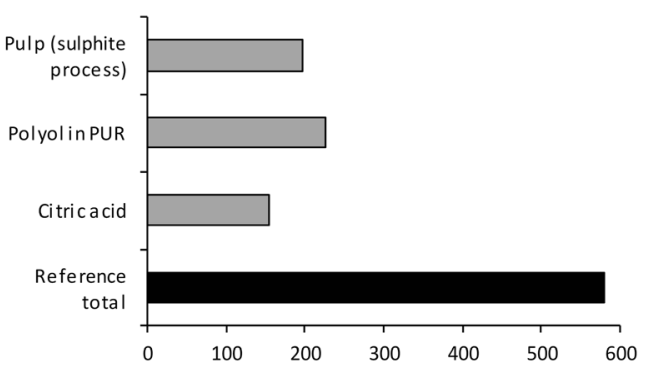

b) $\quad \mathrm{kg} \mathrm{CO}$-eqaccording to biorefinery production

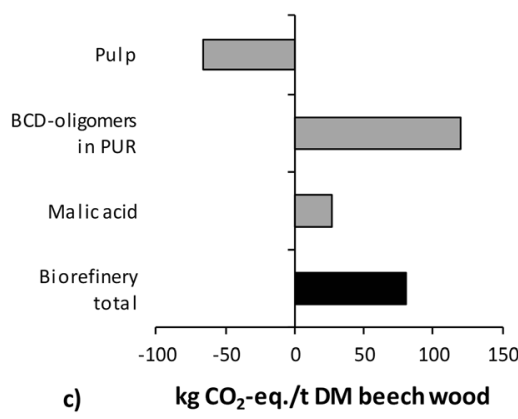

c)

Fig. 5. Greenhouse gas (GHG) emissions of (a) the lignocellulose biorefinery products, (b) the reference products, and (c) savings

oligomers $(2180 € / \mathrm{t})$ showed that marketability is possible, while malic acid $(4750 € / \mathrm{t})$ is not currently competitive. Environmental assessment showed reduced greenhouse gas (GHG) emissions from the production of BCD-oligomers and malic acid and higher GHG emissions from the production of dissolving pulp compared to the reference products. In total, the examined LCB would contribute to the mitigation of global warming.

Acknowledgments We acknowledge the German Federal Ministry of Education and Research (BMBF) for its financial support of the project "KomBiChem ${ }^{\text {Pro }}$-Fein- und Plattformchemikalien aus Holz durch kombinierte chemisch-biotechnologische Prozesse" (grant number: FKZ 031B0083A and 031B0083B).

Funding Information Open Access funding provided by Projekt DEAL.

Abbreviations 5-HMF, 5-Hydroxymethylfurfural; BCD, Base-catalyzed depolymerization; CBP, Chemical-biotechnological processes; $\mathrm{CO}_{2}$-eq, $\mathrm{CO}_{2}$ equivalent; $\mathrm{CW}$, Cold/cooling water; c, Concentration; DAD, Diode array detector; DM, Dry matter; EDTA, Ethylenediaminetetraacetic acid; EDCF, Energy dissipation/circulation factor $\left[\mathrm{W} /\left(\mathrm{m}^{3} \mathrm{~s}\right)\right]$; EE, Electricity; FH, Fired heat; GHG, Greenhouse gas; GPC, Gel permeation chromatography; $\mathrm{HH}$, Hemicellulose hydrolysate; HTHH, Hydrothermally treated hemicellulose hydrolysate; HPLC, High-performance liquid chromatography; HPS, High pressure steam; IBC, Intermediate bulk container; LCA, Life cycle assessment; LCB, Lignocellulose biorefinery; LD, Lignin depolymerization; LPS, Low pressure steam; MAF, Malic acid fermentation; MIBK, Methyl isobutyl ketone; MPS, Medium pressure steam; NF, Nanofiltration; OP, Organosolv pulping; PB, Pulp bleaching; PUR, Polyurethane; $\mathrm{pH}, \mathrm{pH}$ value; REF, Refrigerant; RID, Refractive index detector; VR, Volume reduction; $\mathrm{w}$, Water content; XV, Xylose valorization

Open Access This article is licensed under a Creative Commons Attribution 4.0 International License, which permits use, sharing, adaptation, distribution and reproduction in any medium or format, as long as you give appropriate credit to the original author(s) and the source, provide a link to the Creative Commons licence, and indicate if changes were made. The images or other third party material in this article are included in the article's Creative Commons licence, unless indicated otherwise in a credit line to the material. If material is not included in the article's Creative Commons licence and your intended use is not permitted by statutory regulation or exceeds the permitted use, you will need to obtain permission directly from the copyright holder. To view a copy of this licence, visit http://creativecommons.org/licenses/by/4.0/.

\section{References}

1. Michels J (2009) "Lignocellulose biorefinery - phase 1"- -final scientific and technical report of all project partners. http://www.fnrserver.de/ftp/pdf/berichte/22014406.pdf (accessed: 16 May 2019)

2. Michels J (2014) "Lignocellulose biorefinery — phase 2"- final scientific and technical report of all project partners. https://www.fnrserver.de/ftp/pdf/berichte/22019509.pdf (accessed: 16 May 2019)

3. Laure S, Leschinsky M, Fröhling M et al (2014) Assessment of an organosolv lignocellulose biorefinery concept based on a material flow analysis of a pilot plant. Cellul Chem Technol 48:793-798

4. Nitzsche R, Budzinski M, Gröngröft A (2016) Techno-economic assessment of a wood-based biorefinery concept for the production of polymer-grade ethylene, organosolv lignin and fuel. Bioresour Technol 200:928-939. https://doi.org/10.1016/j.biortech.2015.11. 008

5. Fachagentur Nachwachsende Rohstoffe e. V (2018) Industriepreise Kohlenhydrate interaktiv. Gülzow-Prüzen: Fachagentur Nachwachsende Rohstoffe e.V. (FNR). http://mediathek.fnr.de/ grafiken/daten-und-fakten/preise-und-kosten/industriepreisekohlenhydrate-interaktiv.html (accessed: 18 September 2019)

6. Peter W, Höglinger O (1986) Herstellung von Kunstfaserzellstoff nach dem Organosolv-Aufschlußverfahren. Lenzing Berichte

7. Wiedemann B, Boles E, Keller M (2006) Construction and optimization of pentose-fermenting yeast strains for bioethanol production. Sugar Industry 9(131):627-631

8. Weber C, Farwick A, Benisch F, Brat D, Dietz H, Subtil T, Boles E (2010) Trends and challenges in the microbial production of lignocellulosic bioalcohol fuels. Appl Microbiol Biotechnol 87(4):13031315. https://doi.org/10.1007/s00253-010-2707-z

9. Kwak S, Jo JH, Yun EJ, Jin YS, Seo JH (2019) Production of biofuels and chemicals from xylose using native and engineered yeast strains. Biotechnol Adv 37(2):271-283. https://doi.org/10. 1016/j.biotechadv.2018.12.003

10. Li H, Deng A, Ren J, Liu C, Lu Q, Zhong L, Peng F, Sun R (2014) Catalytic hydrothermal pretreatment of corncob into xylose and furfural via solid acid catalyst. Bioresour Technol 158:313-320. https://doi.org/10.1016/j.biortech.2014.02.059

11. Cheng M-H, Dien BS, Lee DK, Singh V (2019) Sugar production from bioenergy sorghum by using pilot scale continuous hydrothermal pretreatment combined with disk refining. Bioresour Technol 289:121663. https://doi.org/10.1016/j.biortech.2019.121663

12. Köchermann J, Mühlenberg J, Klemm M (2018) Kinetics of hydrothermal furfural production from organosolv hemicellulose and dxylose. Ind Eng Chem Res 57(43):14417-14427. https://doi.org/ 10.1021/acs.iecr.8b03402

13. Gautam A, Menkhaus TJ (2014) Performance evaluation and fouling analysis for reverse osmosis and nanofiltration membranes during processing of lignocellulosic biomass hydrolysate. J Membr Sci 451:252-265. https://doi.org/10.1016/j.memsci.2013.09.042 
14. Sjöman E, Mänttäri M, Nyström M, Koivikko H, Heikkilä H (2008) Xylose recovery by nanofiltration from different hemicellulose hydrolyzate feeds. J Membr Sci 310(1-2):268-277. https://doi.org/10. 1016/j.memsci.2007.11.001

15. Zhou F, Wang C, Wei J (2013) Separation of acetic acid from monosaccharides by NF and RO membranes: performance comparison. J Membr Sci 429:243-251. https://doi.org/10.1016/j.memsci. 2012.11.043

16. Zelle RM, de Hulster E, van Winden WA, de Waard P, Dijkema C, Winkler AA, Geertman JMA, van Dijken JP, Pronk JT, van Maris AJA (2008) Malic acid production by Saccharomyces cerevisiae: engineering of pyruvate carboxylation, oxaloacetate reduction, and malate export. Appl Environ Microbiol 74(9):2766-2777. https:// doi.org/10.1128/AEM.02591-07

17. Toivari $\mathrm{MH}$, Nygård $\mathrm{Y}$, Penttilä $\mathrm{M}$, Ruohonen L, Wiebe MG (2012) Microbial D-xylonate production. Appl Microbiol Biotechnol 96(1):1-8. https://doi.org/10.1007/s00253-012-4288-5

18. Brown SH, Bashkirova L, Berka R, Chandler T, Doty T, McCall K, McCulloch M, McFarland S, Thompson S, Yaver D, Berry A (2013) Metabolic engineering of Aspergillus oryzae NRRL 3488 for increased production of L-malic acid. Appl Microbiol Biotechnol 97(20):8903-8912. https://doi.org/10.1007/s00253013-5132-2

19. Ochsenreither K, Fischer C, Neumann A, Syldatk C (2014) Process characterization and influence of alternative carbon sources and carbon-to-nitrogen ratio on organic acid production by Aspergillus oryzae DSM1863. Appl Microbiol Biotechnol 98(12): 5449-5460. https://doi.org/10.1007/s00253-014-5614-x

20. Goldberg I, Rokem JS, Pines O (2006) Organic acids: old metabolites, new themes. J Chem Technol Biotechnol 81(10):1601-1611. https://doi.org/10.1002/jctb.1590

21. Shrotri A, Kobayashi H, Fukuoka A (2017) Catalytic conversion of structural carbohydrates and lignin to chemicals. Adv Catal 60:59123. https://doi.org/10.1016/bs.acat.2017.09.002

22. Miller JE, Evans L, Littlewolf A et al. (2002) Batch microreactor studies of lignin depolymerization by bases. 1. Alcohol solvents; SAND-Report 2002

23. Miller JE, Evans L, Mudd JE et al. (2002) Batch microreactor studies of lignin depolymerization by bases. 2. Aques solvents; SAND-Report 2002

24. Schmiedl D, Unkelbach G, Graf J et al. (2009) Studies in catalyzed hydrothermal degradation processes on sulphur-free lignin and extractive separation of aromatics SYNTHONs. Proceedings of the Nordic Wood and Biorefinery Conference:189-196

25. Unkelbach G, Schmiedl D, Schweppe R et al. (2010) Catalyzed hydrothermal degradation of lignins from biorefineries to aromatic compounds. Proceedings of the 11th European Workshop on Lignocellulosics and Pulp:57-60

26. Rößiger B, Röver R, Unkelbach G, Pufky-Heinrich D (2017) Production of bio-phenols for industrial application: scale-up of the base-catalyzed depolymerization of lignin. GSC 07(03):193202. https://doi.org/10.4236/gsc.2017.73015

27. Rößiger B, Unkelbach G, Pufky-Heinrich D (2018) Base-catalyzed depolymerization of lignin: history, challenges and perspectives. In book: Lignin — Trends and Applications. doi: https://doi.org/10. 5772/intechopen.72964

28. Lazarova Z, Boyadzhieva S (2004) Treatment of phenol-containing aqueous solutions by membrane-based solvent extraction in coupled ultrafiltration modules. Chemical Engineering Journal 13//100(100//1-3):129-138. doi: https://doi.org/10.1016/j.cej.2004. 01.028

29. Alcudia-León MC, Lucena R, Cárdenas S, Valcárcel M (2011) Determination of phenols in waters by stir membrane liquidliquid-liquid microextraction coupled to liquid chromatography with ultraviolet detection. J Chromatogr A 1218(16):2176-2181. https://doi.org/10.1016/j.chroma.2011.02.033
30. Cruz JM, Domínguez JM, Domínguez H et al. (1999) Solvent extraction of hemicellulosic wood hydrolysates: a procedure useful for obtaining both detoxified fermentation media and polyphenols with antioxidant activity. Food Chem 67(2):147-153. doi: https:// doi.org/10.1016/S0308-8146(99)00106-5

31. Sagehashi M, Nomura T, Shishido H, Sakoda A (2007) Separation of phenols and furfural by pervaporation and reverse osmosis membranes from biomass - superheated steam pyrolysis-derived aqueous solution. Bioresour Technol 98(10):2018-2026. https://doi.org/ 10.1016/j.biortech.2006.08.022

32. European Commission (2017) Horizon 2020 - Work Programme 2016-2017: 20. General Annexes. Decision C(2017)2468

33. Leschinsky M, Unkelbach G, Michels J et al (2012) New pilot-plant facility of the "German Lignocellulose Feedstock Biorefinery Project" in Leuna-experiences with first time operations. Proceedings of NWBC 2012:109

34. Schulze P, Lorenz H, Seidel-Morgenstern A et al. (2014) Method for precipitating lignin from organosolv pulping liquors (WO2016062676A1)

35. Schulze P, Seidel-Morgenstern A, Lorenz H, Leschinsky M, Unkelbach G (2016) Advanced process for precipitation of lignin from ethanol organosolv spent liquors. Bioresour Technol 199: 128-134. https://doi.org/10.1016/j.biortech.2015.09.040

36. Backlund A, Andtbacka S, Dillner B (1995) Process for bleaching pulp without using chlorine containing chemicals. U.S. patent (5415734)

37. Nitzsche R, Gröngröft A, Kraume M (2019) Separation of lignin from beech wood hydrolysate using polymeric resins and zeolitesdetermination and application of adsorption isotherms. Sep Purif Technol 209:491-502. https://doi.org/10.1016/j.seppur.2018.07. 077

38. Köchermann J, Görsch K, Wirth B, Mühlenberg J, Klemm M (2018) Hydrothermal carbonization: temperature influence on hydrochar and aqueous phase composition during process water recirculation. Journal of Environmental Chemical Engineering 6(4):5481-5487. https://doi.org/10.1016/j.jece.2018.07.053

39. Vigneault A, Johnson DK, Chornet E (2007) Base-catalyzed depolymerization of lignin: separation of monomers. Can J Chem Eng 85:906-916

40. Aden A, Ruth M, Ibsen K et al. (2002) Lignocellulosic biomass to ethanol process design and economics utilizing co-current dilute. Technical Report NREL/TP-510-32438, Boston

41. Sassner P, Galbe M, Zacchi G (2008) Techno-economic evaluation of bioethanol production from three different lignocellulosic materials. Biomass Bioenergy 32(5):422-430. https://doi.org/10.1016/j. biombioe.2007.10.014

42. Luo L, van der Voet E, Huppes G (2010) Biorefining of lignocellulosic feedstock - technical, economic and environmental considerations. Bioresour Technol 101(13):5023-5032. https://doi.org/10. 1016/j.biortech.2009.12.109

43. Takkellapati S, Li T, Gonzalez MA (2018) An overview of biorefinery derived platform chemicals from a cellulose and hemicellulose biorefinery. Clean Techn Environ Policy 20(7):16151630. https://doi.org/10.1007/s10098-018-1568-5

44. Kajaste R (2014) Chemicals from biomass - managing greenhouse gas emissions in biorefinery production chains - a review. J Clean Prod 75:1-10. https://doi.org/10.1016/j.jclepro.2014.03.070

45. Verein Deutscher Ingenieure (2012) Economic calculation systems for capital goods and plants 03.100.01, 91.140.10(VDI 6025)

46. Peters MS, Timmerhaus KD, West RE (2004) Plant design and economics for chemical engineers, Chemical Engineering Series, 5th edn. McGraw-Hill, Boston

47. Chauvel A, Fournier G, Raimbault C (2003) Manual of Process Economic Evaluation, New, Revised and, Expanded edn. ED TECHNIP, Paris 
48. Jenkins S (2018) Chemical Engineering Plant Cost Indexes CEPCI. https://www.chemengonline.com/cepci-updates-january-2018prelim-and-december-2017-final/?printmode $=1$ (accessed: 03 April 2019)

49. Verband der Chemischen Industrie e. V. (2018) Chemiewirtschaft in Zahlen 2018. https://www.vci-nord.de/fileadmin/vci-nord/ Bilder/publikationen/chemiewirtschaft-in-zahlen-2018-web.pdf (accessed: 17 April 2020)

50. International Panel of Climate Change (2007) Climate Change 2007: The Physical Science Basis: Contribution of Working Group I to the Fourth Assessment Report of the Intergovernmental Panel on Climate Change [Solomon, S., D. Qin, M. Manning, Z. Chen, M. Marquis, K.B. Averyt, M. Tignor and H.L. Miller (eds.)]. Cambridge University Press, Cambridge, United Kingdom and New York, NY, USA

51. Pawelzik P, Carus M, Hotchkiss J, Narayan R, Selke S, Wellisch M, Weiss M, Wicke B, Patel MK (2013) Critical aspects in the life cycle assessment (LCA) of bio-based materials - reviewing methodologies and deriving recommendations. Resour Conserv Recycl 73:211-228. https://doi.org/10.1016/j.resconrec.2013.02.006

52. ifu Hamburg GmbH (2018) Umberto LCA+10.0.3, Hamburg

53. Klöpffer W, Grahl B (2014) Life Cycle Assessment (LCA): A Guide to Best Practice. Wiley-VCH Verlag GmbH \& Co. KGaA, Weinheim, Germany

54. Frischknecht R, Jungbluth N, Althaus H-J, Doka G, Dones R, Heck T, Hellweg S, Hischier R, Nemecek T, Rebitzer G, Spielmann M (2005) The ecoinvent database: overview and methodological framework (7 pp). Int J Life Cycle Assess 10(1):3-9. https://doi. org/10.1065/lca2004.10.181.1

55. Wernet G, Bauer C, Steubing B, Reinhard J, Moreno-Ruiz E, Weidema B (2016) The ecoinvent database version 3 (part I): overview and methodology. Int J Life Cycle Assess 21(9):1218-1230. https://doi.org/10.1007/s11367-016-1087-8

56. McDonough T (1991) Oxygen delignification. Bleaching: a Tappi press anthology of published papers 1987-1990(318):1-9

57. Richter BE, Jones BA, Ezzell JL, Porter NL, Avdalovic N, Pohl C (1996) Accelerated solvent extraction: a technique for sample preparation. Anal Chem 68(6):1033-1039. https://doi.org/10.1021/ ac9508199

58. Sixta H (2006) Handbook of Pulp. Wiley-VCH, Weinheim, Chichester

59. Köchermann J, Schreiber J, Klemm M (2019) Conversion of dxylose and hemicellulose in water/ethanol mixtures. ACS Sustain Chem Eng. https://doi.org/10.1021/acssuschemeng.9b01697

60. Jung H, Kappen J, Hesse A et al. (2011) Wasser- und Abwassersituation in der deutschen Papier- und Zellstoffindustrie - Ergebnisse der Wasserumfrage 2010. Wochenblatt für Papierfabrikation:737-739

61. Jönsson A-S, Nordin A-K, Wallberg O (2008) Concentration and purification of lignin in hardwood kraft pulping liquor by ultrafiltration and nanofiltration. Chem Eng Res Des 86(11):1271-1280. https://doi.org/10.1016/j.cherd.2008.06.003

62. Heinonen J, Sanlaville Q, Niskakoski H, Tamper J, Sainio T (2017) Separation and recovery of lignin from hydrolysates of lignocellulose with a polymeric adsorbent. Sep Purif Technol 186: 125-134. https://doi.org/10.1016/j.seppur.2017.06.001

63. Turton R (ed) (2012) Analysis, Synthesis, and Design of Chemical Processes, 4th ed. Prentice Hall international series in the physical and chemical engineering sciences. Prentice Hall, Upper Saddle River, NJ

64. Centrales Agrar-Rohstoff Marketing- und Energie-Netzwerk e.V (2018) Preisentwicklung bei Waldhackschnitzeln - der Energieholz-Index

65. F.O. Licht (2018) World Ethanol \& Biofuels Report

66. Thaore V, Chadwick D, Shah N (2018) Sustainable production of chemical intermediates for nylon manufacture: a techno-economic analysis for renewable production of caprolactone. Chem Eng Res Des 135:140-152. https://doi.org/10.1016/j.cherd.2018.05.026

67. ICIS (2018) Chile sulphuric acid 2019 annual contracts spike on supply shortages (ICIS News)

68. EUWID - Papier und Zellstoff (2019) $\mathrm{NaOH}$-Anbieter wollen Notierung über der $600 €$-Marke etablieren

69. ICIS (2018) OUTLOOK '18: US caustic soda could push higher on restricted global supply (ICIS News)

70. Brynolf S, Taljegard M, Grahn M, Hansson J (2018) Electrofuels for the transport sector: a review of production costs. Renew Sust Energ Rev 81:1887-1905. https://doi.org/10.1016/j.rser.2017.05. 288

71. Echemi Technology Co., Ltd. (2019) ECHEMI-Hydrogen Peroxide Price Analysis

72. Fertecon (2017) Sulphuric Acid Report: Weekly Review of the Sulphuric Acid Market

73. ICIS (2018) Phosphates prices up on good demand, tight supply and higher feedstock costs (ICIS News)

74. ICIS (2019) Morocco's OCP settles Q1 India phosphoric acid price at $\$ 18 /$ tonne decrease (ICIS News)

75. Müller-Langer F (2012) Analyse und Bewertung ausgewählter zukünftiger Biokraftstoffoptionen auf der Basis fester Biomasse. DBFZ-Report, Leipzig

76. European Commission (2018) Energy Statistics—Prices of Natural Gas and Electricity

77. European Commission (2018) Energy Statistics - Prices of Natural Gas and Electricity

78. Fachagentur Nachwachsende Rohstoffe e.V (2014) Marktanalyse nachwachsende Rohstoffe. Gülzow-Prüzen: Fachagentur Nachwachsende Rohstoffe e.V. (FNR). Schriftenreihe Nachwachsende Rohstoffe

79. ICIS (2019) Jan prices trend stable for Europe polyols despite lower costs on margin pressure (ICIS News)

80. RedCorn R, Engelberth AS (2016) Identifying conditions to optimize lactic acid production from food waste co-digested with primary sludge. Biochem Eng J 105:205-213. https://doi.org/10.1016/ j.bej.2015.09.014

81. Pharmacompass (2016) API Imports and Exports from India: PharmaCompass' API Reference Price for Malic Acid

Publisher's Note Springer Nature remains neutral with regard to jurisdictional claims in published maps and institutional affiliations. 